Article

\title{
Modeling the Effects of Explicit Urban Canopy Representation on the Development of Thunderstorms above a Tropical Mega City
}

\author{
José Luis Flores-Rojas ${ }^{1, *(1)}$, Augusto José Pereira-Filho ${ }^{2}$ (), Hugo Abi Karam ${ }^{3}$, Felipe Vemado ${ }^{2}$, \\ Valéry Masson ${ }^{4}$ and Fey Yamina Silva-Vidal ${ }^{1}$ \\ 1 Geophysical Institute of Perú Calle Badajoz 169 Urb. Mayorazgo IV Etapa. Ate, Lima 15012, Peru \\ 2 Universidade de São Paulo, São Paulo-Instituto de Astronomia, Geofísica e Ciências Atmosféricas, \\ Rua do Matão 1226, São Paulo, Brazil \\ 3 Universidade Federal de Rio de Janeiro, Rio de Janeiro-Instituto de Geociências, Rua Athos da Silveira \\ Ramos, Cidade Universitária-Ilha do Fundão, Rio de Janeiro 274, Brazil \\ 4 Centre National de Recherches Météorologiques, Météo-France/CNRS, 31057 Toulouse, France \\ * Correspondence: jflores@igp.gob.pe; Tel.: +51-924-133-957
}

Received: 10 May 2019; Accepted: 19 June 2019; Published: 27 June 2019

\begin{abstract}
The effects of an explicit three dimensional (3D) urban canopy representation on the development of convective thunderstorms were analyzed with the tropical town energy budget (tTEB) scheme integrated into the advanced regional prediction system (ARPS). The study provides a detailed description of the procedure to couple the system ARPS-tTEB and analyzed the simulation results of the 12 January 2015 sea-breeze event that developed a severe thunderstorm above the metropolitan area of São Paulo (MASP), Brazil. The simulation used realistic boundary and initial conditions from the Global Forecast System (GFS) and sea surface temperature (SST) from the Tropical Rainfall Measurement Mission (TRMM). The system ARPS-tTEB runs of up to $3 \mathrm{~km}$ horizontal resolution were carried out with high resolution topography features and land-use types currently available for Southeastern Brazil. The simulated spatial distribution of precipitation was verified against the Climate Prediction Center Morphing Technique (CMORPH), the Global Precipitation Measurement (GPM) and the São Paulo weather radar (SPWR) precipitation estimates by indexes scores. Time series of grid precipitation estimates (ARPS-tTEB and SPWR) and point measurements (rain gauges) were evaluated with a Bayesian statistical method. Results indicate that the urban area of the MASP modulates the precipitation spatial distribution over it. Furthermore, phase and amplitude precipitation accuracy increased with the 3D urban canyon and the urban energy budget scheme in relationship to control runs without urban environment effects.
\end{abstract}

Keywords: urban energy fluxes; convective thunderstorms; ARPS; tTEB

\section{Introduction}

Convective storm systems range from ordinary cells to large mesoscale clusters. Thunderstorms can be associated to tornadoes, flash floods, straight-line winds and large hailstone damaging [1] under moderate to high convective available potential energy (CAPE) and ample vertical wind shear [2,3]. There are several characteristic features associated with these storms including a propensity for steadiness and longevity (storm lifetimes of two hours or more, principal intense and ciclonically rotating updraft and large hail [4]. Several non-hydrostatic atmospheric models were developed and applied to numerical simulations and operational Numerical Weather Prediction (NWP). Among them, the advanced regional prediction system (ARPS) [5] was developed at the Center for Analysis and Prediction of Storms (CAPS) at the University of Oklahoma. The ARPS is designed to serve as an 
effective tool for basic and applied research and as a system suitable for explicit prediction of convective storms as well as weather systems at other scales. The model includes physics parameterization schemes, important for explicit prediction of convective storms as well as the prediction of flows at larger scales.

A little over one percent of the surface of the Earth is urban, but is expected to increase rapidly in the next decades [6]. More than $80 \%$ of the population of the world will live in cities by 2050 [7]. The urban canopy is formed by the assemblage of buildings, trees, and other objects composing a city and the spaces between them. The urban environment is the entire volume of air above the urban canopy that is influenced by its surface characteristics and by the activities within it [8]. The urban environment extends upward to about ten times the height of the buildings in the urban area [9]. Rural and urban surfaces differ in albedo and thermal properties besides anthropic heating. The latter converts more solar radiation into turbulent sensible heat with surface temperatures higher than in the former yielding an urban heat island (UHI) [9]. It enhances convective instability and storms by changing boundary-layer processes. Several studies indicate urban-induced changes in precipitation patterns is most likely due to one or more factors: (1) enhancement, creation or displacement of a mesoscale circulation which cause atmospheric instability, (2) increase in low-level convergence resulting from enhanced surface roughness, (3) addition of cloud condensation nuclei $(\mathrm{CCN})$ modifying microphysical and dynamic processes and (4) addition of urban industrial sources of moisture modifying the low-level atmospheric moisture content [10]. The Metropolitan Meteorological Experiment (METROMEX) carried out in the USA in the 70s studied changes in convective precipitation in major cities [11,12]. Results showed that urban effects produce increased precipitation observed within and 50-75 km downwind of the city, reflecting increases of 5-25\% over the background values $[13,14]$.

By studying the interaction between the sea breeze circulation (SBC) and the urban heat island circulation (UHIC) around the metropolitan area of São Paulo (MASP) under weak synoptic forcing was concluded that precipitation accumulation was higher above the MASP $[15,16]$. It was shown that convection is triggered by the incoming sea-breeze front causing lifting and instability near surface and by intense vertical sensible heat fluxes within MASP. Also was suggested that higher roughness caused by urban structures and higher $\mathrm{CCN}$ from anthropic sources were most probably related to the increase in the amount of precipitation. However, thermodynamic and dynamic effects tend to override aerosol effects in severe thunderstorm environment conditions and topographic effects can also induce vertical motion and convection [17].

Realistic urban heat flux schemes can be incorporated into atmospheric models to study different urban effects. By integrating the the town energy budget (TEB) scheme [18] with the cloud-resolving regional atmospheric modeling system (RAMS) [19] to simulate the 8 June 1999 Saint Louis City thunderstorms in Missouri, it was shown that turbulent heat fluxes downwind of the city rather that urban roughness caused the thunderstorm by altering the surface energy balance (SEB) [20]. Moreover, it was investigated whether or not TEB implemented into RAMS could emulate record $24 \mathrm{~h}$ precipitation accumulation in Mumbai, India, on 26 July 2005 [21]. Results for this synoptically active rainfall event indicate updrafts and precipitation were significantly affect by urban heterogeneities and surface temperatures.

A recent contribution simulated a wintertime local circulation in the MASP using tropical town energy budget (tTEB) scheme [22] coupled to ARPS [23]. Results show that stronger convergence caused by the UHI in the center of the MASP accelerated the sea-breeze front, it later reached the MASP interacting with the UHI circulation, increasing moisture convergence and strengthening updrafts. Similar results were obtained for the same region using TEB scheme and RAMS model but without topographic effects [24]. An evaluation of physical mechanisms associated to urbanization in Manaus City, Brazil, using TEB and RAMS showed microclimate changes related to urban growth and changes in the local microclimate [25]. Recently, the coupled system ARPS-tTEB was used to simulate heavy rainfall episodes of 26 August 2011, 23 July and 12 August 2013 in the Tokyo Metropolitan Area (TMA). 
The simulations improved the south and east SBC of the TMA and its urban heat island effect on the spatial distribution of precipitation [26].

Motivated by these considerations, the present contribution integrates the tTEB scheme [22] into the ARPS model [5] to simulate the effects of urban environment on the development of convective thunderstorm on the MASP for the event of 12 January 2015. The system ARPS-tTEB is a proposed tool to study urbanization effects on meteorological conditions under various scenarios. The impact of urban fluxes of momentum, sensible and latent on the development of deep convection is analyzed using realistic initial and boundary conditions. The present work is the first to analyze effects of explicit urban canopy representation on the simulation of the development of thunderstorms above the MASP. The proposed scheme will be useful to future works that intend to study the effects of urban environment on the development of thunderstorms by integrating urban energy budget schemes into ARPS system since it does not have an explicit representation at the present.

Several efforts of intercomparison of the urban surface schemes has been done by the community $[27,28]$. Even the TEB urban surface scheme was also tested along with the other schemes [29]. The intercomparison of urban schemes expresses the similar capacity of the different schemes in simulating the urban conditions, not having one that stands out over the others in an evident way. However, it was emphasized that the role of precipitation was not highlighted in the intercomparison. Therefore, the analysis of the complex interactions between the urban surface conditions, the development of the urban boundary layer and the triggering and development of thunderstorms over the MASP, proposed in the present contribution, have great importance.

The main features of the MASP are presented in Section 2. The models ARPS and tTEB are described in Section 3. The coupled system ARPS-tTEB is described in Section 4.1. The model configuration and experimental design used for the experiments are described in Section 4.2. Performance indexes and a Bayesian estimation with T-test statistics are in Sections 4.3 and 4.4. A synoptic analysis for the event of 12 January 2015 is shown in Section 4.5. Precipitation and surface weather variables measurements are in Section 4.6. Results and discussions are in Sections 5 and 6 concludes the paper.

\section{Study Area}

The MASP is located in south-eastern Brazil $\left(23^{\circ} 35^{\prime} 55^{\prime \prime} \mathrm{S}-46^{\circ} 37^{\prime} 46^{\prime \prime} \mathrm{W}\right)$, about $60 \mathrm{~km}$ from the Atlantic Ocean on $770 \mathrm{~m}$ plateau above sea level. It shelters the largest industrial complex of South America with a population of $23.4 \mathrm{mi}$ inhabitants. Its 39 cities occupy a total area of $8051 \mathrm{~km}^{2}$, and an urbanized area of $2700 \mathrm{~km}^{2}$ [30]. The population increased twenty fold in the last century when intense urbanization took place with significant environmental and microclimate changes [31]. In the MASP, the observed changes in precipitation patterns may be related to several factors, probably the most important is the UHI phenomenon. A recent study, which uses a historical series of meteorological data, shows an increase in the frequency of events with moderate and extreme precipitation from the mid-1970s [32]. Also was possible to identify a decrease of days with light rains $\left(<5 \mathrm{~mm} \mathrm{day}^{-1}\right)$ and an increase in the frequency of days with extreme temperature values $\left(>32^{\circ} \mathrm{C}\right)$ and that milder minimum temperatures have become less common in the last 30 years [32].

The South Atlantic High Pressure System (SAHPS) modulates the yearly total precipitation over Eastern Brazil, including the MASP, but also other weather transients as fronts, squall lines, mesoscale complex systems and isolate convection specially those induced by local circulation such as sea breeze fronts and heat island convergence. Moving polar highs reach the MASP throughout the year but more intense cold intrusions occur during fall and winter [33]. NW-SE low level jets transport moisture from Amazonia to south-eastern Brazil and is known as the South Atlantic Convergence Zone [34]. Prevailing surface air circulation over the MASP are NE and NW during the night and early morning in association to the SAHPS.

The SBC develops during the afternoon and early evening when surface winds intensify and shift to SE and SW. The SBC reaches the MASP more than half of days of the year [16]. It intensifies from 
the sea shores of São Paulo State towards Serra do Mar scarp, injecting Atlantic Ocean moisture in the MASP. The SBC strength inland is modulated by the UHI effect above the MASP, topography effects and atmospheric stability. Indeed, summer precipitation is more intense over the urban area of the MASP due to the combined effects of the UHIC and SBC [15]. All 125 SBC-UHIC deep convection episodes between 2005 and 2008 indicated an anomaly of $600 \mathrm{~mm}$ above the MASP. The UHI effect induces a thermal low and convergence over the MASP. Moreover, most episodes of heavy precipitation associated with the SBC occur between October and April (Spring-Summer). In general, no deep convection is associated to the SBC during May and September (Fall-Winter) [16].

\section{The ARPS Model and the tTEB Scheme}

The ARPS was developed by the Center for Analysis and Prediction Storms at the University of Oklahoma. It includes modern physics parameterization schemes important for the explicit prediction of convective storms, as well as the prediction of flows at larger scales [5]. The planetary-boundary-layer and surface-layer parameterizations are necessary to evaluate the contribution of the land surface in terms of the sensible and latent heat exchange with the atmosphere, as the soil surface temperature and moisture content directly appear in the surface-flux calculations.

Numerical weather prediction is often sensitive to the surface fluxes of heat, momentum and moisture. A stability- and roughness-length-dependent surface-flux model is available in the ARPS model based on a modified formulation proposed by Businger [35], who analyzed the wind-speed and temperature profiles for a wide range of stability conditions in the context of Monin-Obukhov similarity theory. Moreover, a procedure proposed based on the exact analytical solutions of the Monin-Obukhov stability parameters in terms of the gradient and bulk Richardson numbers for both stable and unstable atmospheric conditions was used in the flux calculations [36]. In addition, Businger's formulation was further modified so that the results are more realistic for highly stable or highly unstable conditions [37].

In general, urban-canopy models represent the physics of the system more accurately by solving the surface energy balance (SEB) for a realistic three-dimensional urban canopy, and can be separated into two categories. (1) Models where the canopy air is parameterized. These are referred to as single-layer models, because there is direct interaction with only one atmospheric layer above the uppermost roof level. This means that, when coupled with a mesoscale atmospheric model, the base of the atmospheric model is located at the roof level. (2) Models using a drag approach [38]. These are so-called multilayer models, because several air layers are explicitly influenced by the building (down to the road surface), because the air layers extend down into the canopy.

The simplest of the single-layer models is the TEB scheme [18], which simulates the turbulent fluxes (heat, momentum and mass) into the atmosphere at the surface of a mesoscale atmospheric model covered by buildings, roads, or any artificial material. The TEB scheme parameterizes both the urban surface and the roughness sublayer, so that the atmospheric model only accounts for a constant-flux layer as its lower boundary. The scheme reproduces the damping of the daytime turbulent heat flux by the heat-storage flux observed in cities.

For cities located in tropical regions, the tTEB scheme of [22] uses the original equations of the TEB scheme [18]. However, several modifications were implemented to enable the simulation of the surface conditions of tropical cities. The most important modifications include: (a) local-scaling approaches for obtaining flux-gradient relationships in the roughness sublayer; (b) the Monin-Obukhov similarity framework in the inertial sublayer; (c) increasing aerodynamic conductance toward more unstable conditions; (d) a modified urban subsurface drainage system to transfer the intercepted rainwater by roofs to the roads and; (e) long-wave infrared irradiances inside the urban canyon calculated using multiple reflections [39].

More details related to estimation of the turbulent energy fluxes in the inertial sub-layer (ISL) and roughness sub-layer (RSL), and to the evolution of the water reservoir used in the tTEB scheme, can be found in [22,23]. The increasing resolution of atmospheric models (up to $0.5 \mathrm{~km} \times 0.5 \mathrm{~km}$ ) 
allows explicit representation of urban areas, so that modeling the SEB of the urban environment becomes crucial when urban effects are simulated by non-hydrostatic atmospheric models. Next, the step-by-step procedure of the coupled ARPS-tTEB system is described.

Currently, the surface parameterization used by the ARPS model does not consider the SEB generated by the urban environment. As a consequence, to analyze the effects of the urban environment on the development of convective thunderstorms, it is necessary to couple the model with a town energy budget scheme (tTEB), as was described in detail in [23] and briefly summarized in Section 4.1.

\section{Methodology}

\subsection{Coupling the ARPS with the tTEB Scheme}

The procedure to couple the non-hydrostatic atmospheric model ARPS and the tTEB scheme (Section 3) is summarized in this section. The integration of them both made it possible to study urban micro-climates, and increased the accuracy of short-term forecasting (nowcasting) models. Figure 1 shows a flow chart of the main steps to integrate ARPS and tTEB scheme. The tTEB variables were transferred to the main ARPS subroutine, the driven subroutine and the surface-physics subroutine. If vegetation cover was of the urban type (originally semi-desert in ARPS), then the dynamic and radiative variables used in the ARPS model were transferred to the tTEB scheme with urban parameters set as constants. Next, the tTEB output variables modified ARPS variables and recalculates the surface-energy fluxes over the urban environment. Finally, the urban energy fluxes and surface variables were transferred to ARPS surface-physics subroutine, closing a cycle.

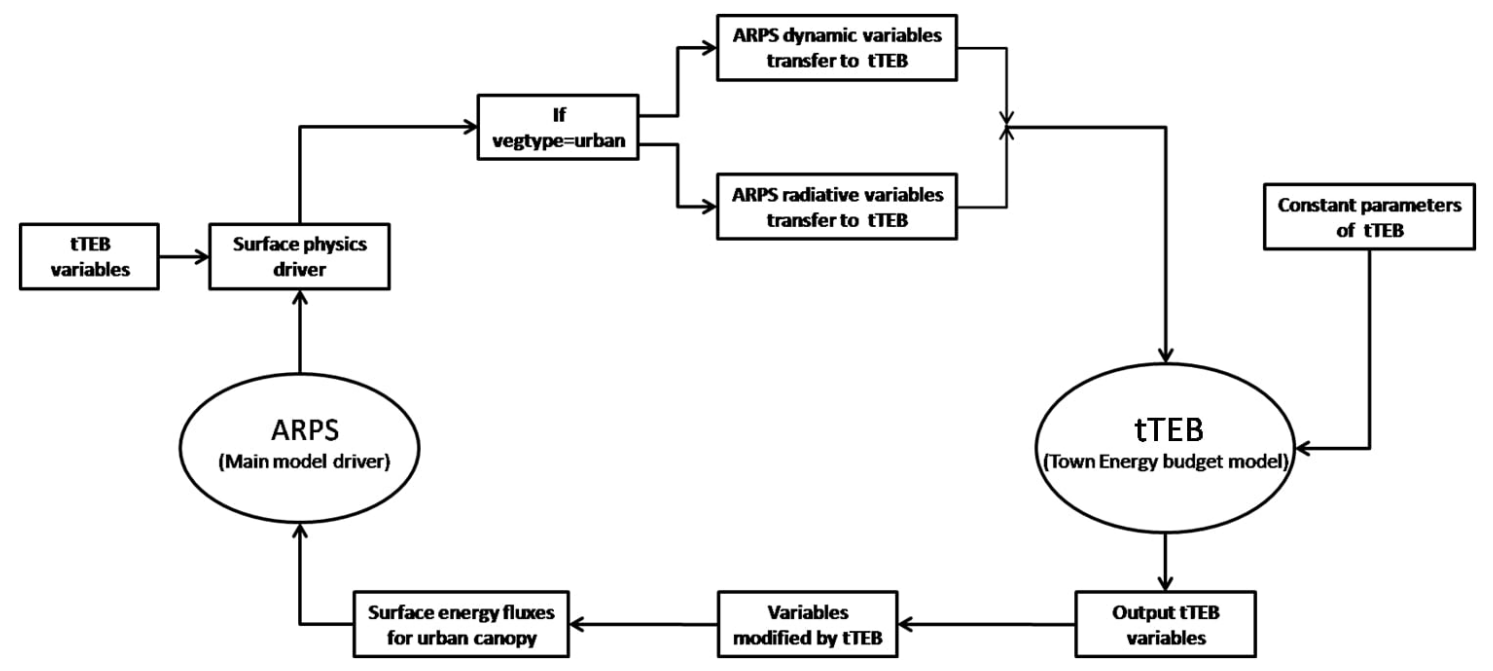

Figure 1. Flow chart indicating the coupling of the advanced regional prediction system (ARPS) model with the tropical town energy budget (tTEB) scheme. The dynamic and radiative variables from the ARPS model are transferred to the tTEB scheme and the output surface variables of the tTEB scheme are returned to the ARPSs model.

The surface temperature and the surface water content used by the ARPS was obtained by a combination between the output temperatures of the roofs, walls and roads obtained by the tTEB scheme [23]. The tTEB scheme considered a variable draining ratio to determine the time evolution of water accumulation over roofs and roads [40]. a recent contribution [23] gives additional details on the estimation of surface temperature, the evolution of water accumulation and the surface-water content in the urban canyon (roof, roads and walls), complex drag and surface energy fluxes in the atmospheric flow used in the present study. 


\subsection{Model Configuration and Experimental Design}

Two experiments were made to evaluate the performance of the coupling ARPS-tTEB system in simulating the effects of urban energy fluxes on the development of convective storms under real conditions to simulate the thunderstorm event above the MASP on 12 January 2015. The main features of both simulations are showed in Table 1 . The first was a control run experiment that does not take into account the urban SEB, and considers the urban area as a semi-desert canopy with the biophysical parameters shown in Table 2. The second one with tTEB experiment included the effects of the urban SEB based on the urban surface properties shown in Table 3.

The simulations used three nested grids with 27,9 and $3 \mathrm{~km}$ grid spacings centered at $23.54^{\circ} \mathrm{S}$, $46.63^{\circ} \mathrm{W}$ (Figure 2a). The domain of $27 \mathrm{~km}$ had $143 \times 143$ horizontal grid points covering the eastern region of South America, and a time step of $10 \mathrm{~s}$ (Figure 2a). The domains of $9 \mathrm{~km}$ and $3 \mathrm{~km}$ simulated the general mesoscale setting with $143 \times 143$ horizontal grid points and a time step of $6 \mathrm{~s}$. A total of 43 vertical hyperbolic tangent function was used, varying from $20 \mathrm{~m}$ to a maximum altitude of $20.5 \mathrm{~km}$.

Table 1. Summary of basic model configuration.

\begin{tabular}{cc}
\hline Category & Options \\
\hline Governing equations & 3D, nonhydrostatic, compresible \\
Grid stagger & vertical hyperbolic tangent \\
Time differencing & Leapfrog and forward time differences \\
Turbulence closure & 1.5 TKE turbulent mixing \\
Upper boundary & GFS model (resolution: $1^{\circ}$ ) \\
Lateral boundaries & GFS model (resolution: $1^{\circ}$ ) \\
Mycrophysics & Ref. [41] ice microphysics scheme \\
Cumulus parameterization & Ref. [42] scheme for domain of 27 km \\
Radiation physics & Atmospheric radiation transfer parameterization \\
Surface physics & tTEB scheme for urban canopy and two layer \\
& force-restore model for vegetation canopy \\
\hline
\end{tabular}

The ARPS-tTEB system was used at the $3 \mathrm{~km}$ domain containing MASP. Figure $2 \mathrm{~b}$ shows the vegetation cover for the $3 \mathrm{~km}$ domain with urban type set to 13. The topography and pressure fields over the MASP are shown in Figure 2c. Horizontally inhomogeneous initial and boundary conditions are specified by GFS $1^{\circ}$ resolution dataset. The simulation runs started at 1800 UTC on 21 August 2014 until 0000 UTC on 23 August 2014 ( 30 h). The 1.5 order turbulent kinetic energy (TKE) closure scheme for sub grid boundary-layer turbulence. Ice microphysics scheme by [41] was used. It includes two liquid phases (cloud and rain) and three ice categories (ice cloud, snow and hail or graupel). The scheme assumes spherical hydrometeor exponential size distributions for rain, snow and hail/graupel. Control runs were performed with surface physics of sandy loam soil type and semi-desert vegetation. Urban and vegetation grid cells from the Global Ecosystems Database that adapts biophysical parameters such as the leaf area index, fractional coverage, displacement height, roughness height, albedo and emissivity. 

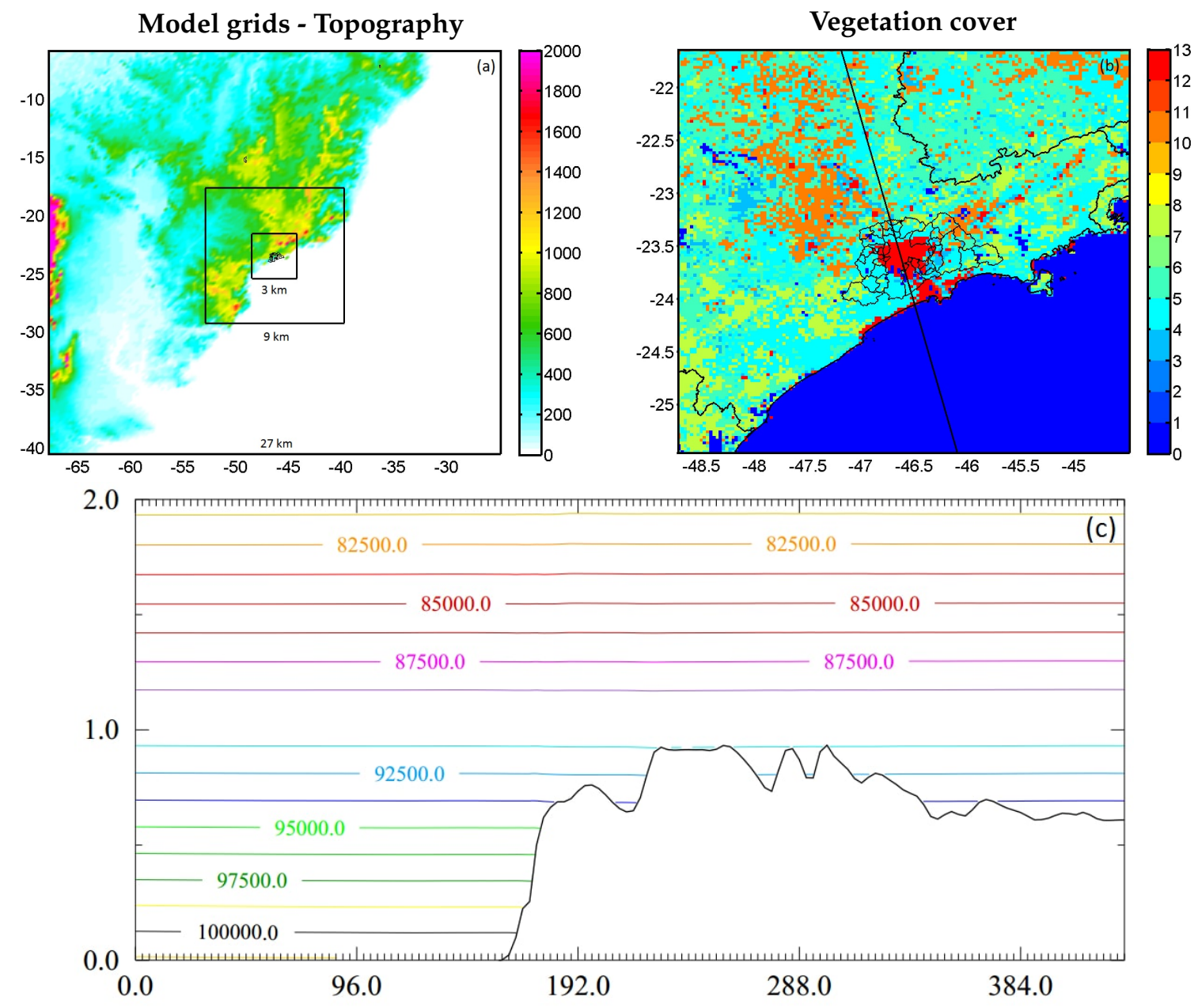

Figure 2. (a) The three model domains used in the simulations $(27,9$ and $3 \mathrm{~km})$, with the background showing the topography of the region of the inner domain $(3 \mathrm{~km})$. (b) Types of vegetation cover used in ARPS for inner most domain (3 km). (0) Water, (1) desert, (2) tundra, (3) grassland, (4) grassland with shrub cover, (5) grassland with three cover, (6) deciduous forest, (7) evergreen forest, (8) rain forest, (9) ice, (10) cultivation, (11) bog or marsh, (12) dwarf shrub and (13) semi-desert. The urban canopy replaced semi-desert canopy (13). (c) Elevation cross section for inner most domain (3 km) indicated by the black line in (b) and pressure fields in $\mathrm{Pa}$.

Predominant land-use land classes in MASP were grassland, deciduous forest and semi-desert land, considered in this work as urban canopy (Figure 2b). The biophysical parameters for these vegetation types are in Table 2 . The momentum fluxes inside the urban canopy and at the first model level are strongly determined by the roughness length $\left(z_{\circ}\right)$ and the zero-plane displacement $(d)$, which were too small for the MASP (see Table 2). For the case of regularly -built towns, roughness lengths were found to lie between 0.7 to $1.5 \mathrm{~m}$. In the case of a high-rise urban surface $(\mathrm{h} \geq 20 \mathrm{~m})$, which is the case for the central part of MASP, it has been suggested roughness-length values greater than $2.0 \mathrm{~m}$ [43]. However, here we used the morphometric formulae propesed by Kastner [44] to estimate $z_{\circ}$ and $d$.

The urban area of the MASP was about $2700 \mathrm{~km}^{2}$ reflecting the increased urbanization process in Brazil $[30,45,46]$ divided the MASP into two different land-use land classes: urban type 1, which predominantly contains high-rise buildings and covers approximately $300 \mathrm{~km}^{2}$ and urban type 2, which mainly contains residential and industrial regions and covers approximately $2400 \mathrm{~km}^{2}$ (Table 3). These two regions were defined from LANDSAT-5 imagery and are classified according to the original land-cover categories provided by the International Geosphere-Biosphere Programme (IGBP). 
From these two urban types, a set of average values proportional to the urban areas for each parameter was calculated (Table 3).

Table 2. Some parameters used in the advanced regional prediction system (ARPS) model for three different types of vegetation cover.

\begin{tabular}{cccccc}
\hline $\begin{array}{c}\text { Parameter } \\
\text { Class }\end{array}$ & Albedo & Emissivity & $\begin{array}{c}\text { Leaf Area } \\
\text { Index }\end{array}$ & $\begin{array}{c}\text { Roughness } \\
\text { Length } \mathbf{z}_{\circ}(\mathbf{m})\end{array}$ & $\begin{array}{c}\text { Zero-Plane } \\
\text { Displacement d (m) }\end{array}$ \\
\hline Grassland-shrub cover & 0.18 & 0.96 & 5.0 & 0.51 & 3.6 \\
Grassland-tree cover & 0.20 & 0.95 & 6.0 & 0.06 & 0.7 \\
Semi-desert (urban) & 0.15 & 0.90 & 4.8 & 0.80 & 1.1 \\
\hline
\end{tabular}

Table 3. Differences between the parameters for the two urban areas above the metropolitan area of São Paulo (MASP) [46] and the average values used in the tropical town energy budget (tTEB) scheme.

\begin{tabular}{cccc}
\hline Parameter & Urban 1 & Urban 2 & Average \\
\hline Building height $(\mathrm{m})$ & 50.0 & 5.0 & 10.0 \\
Building aspect ratio (height/length) & 2.0 & 1.0 & 1.2 \\
Canyon aspect ratio (height/width) & 3.0 & 0.5 & 0.9 \\
Fractional area covered by artificial material & 0.9 & 0.8 & 0.8 \\
Fractional area covered by buildings & 0.9 & 0.8 & 0.8 \\
Traffic sensible heat release $\left(\mathrm{W} \mathrm{m}^{-2}\right)$ & 30.0 & 20.0 & 21 \\
Traffic latent heat release $\left(\mathrm{W} \mathrm{m}^{-2}\right)$ & 7.0 & 5.0 & 5.3 \\
Industrial sensible heat release $\left(\mathrm{W} \mathrm{m}^{-2}\right)$ & 20.0 & 30.0 & 28.5 \\
Industrial latent heat release $\left(\mathrm{W} \mathrm{m}^{-2}\right)$ & 40.0 & 50.0 & 48.5 \\
\hline
\end{tabular}

Buildings, road materials and the average geometry data were required in the tTEB scheme. These urban parameters are shown in Table $4[9,18]$. All tTEB parameters were kept constant and for average conditions. Non-urban land-use classes in the model domain were always parameterized via the force-restore scheme [47]. Average parameters in Table 3 drove the model with an acceptable degree of approximation. As an aside, updated and publicly available urban-morphology datasets for urban modelling is needed. The GFS one-degree resolution sea surface temperature (SST) used by ARPS were replaced by Tropical Rainfall Measurement Mission (TRMM) $0.25^{\circ}$ resolution daily SST [21]. TRMM daily SSTs are lower with higher gradients near the coast of São Paulo State compared to GFS ones (not shown). SST differences yield realistic gradients generating a convergence zone above the MASP.

Table 4. Average values of parameters for the urban landscape used in the tTEB scheme based on a previous contribution [18].

\begin{tabular}{|c|c|}
\hline Parameter & Value \\
\hline Roof layers 1,2 and 3 thicknesses $(\mathrm{m})$ & $0.1,0.1,0.1$ \\
\hline Wall layers 1, 2 and 3 thicknesses (m) & $0.1,0.1,0.1$ \\
\hline Road layers 1, 2 and 3 thicknesses $(\mathrm{m})$ & $0.1,0.1,0.1$ \\
\hline Roof layers 1,2 and 3 thermal conductivity $\mathrm{W} \mathrm{m}^{-1} \mathrm{~K}^{-1}$ & $0.81,0.81,0.81$ \\
\hline Wall layers 1,2 and 3 thermal conductivity $\mathrm{W} \mathrm{m} \mathrm{m}^{-1} \mathrm{~K}^{-1}$ & $0.81,0.81,0.81$ \\
\hline Road layers 1,2 and 3 thermal conductivity $\mathrm{W} \mathrm{m}^{-1} \mathrm{~K}^{-1}$ & $0.81,0.81,0.81$ \\
\hline Roof layers 1,2 and 3 heat capacity $\mathrm{J} \mathrm{m}^{-3} \mathrm{~K}^{-1}$ & $10^{6}, 10^{6}, 10^{6}$ \\
\hline Wall layers 1,2 and 3 heat capacity $\mathrm{J} \mathrm{m}^{-3} \mathrm{~K}^{-1}$ & $10^{6}, 10^{6}, 10^{6}$ \\
\hline Road layers 1,2 and 3 heat capacity $\mathrm{J} \mathrm{m}^{-3} \mathrm{~K}^{-1}$ & $10^{6}, 10^{6}, 10^{6}$ \\
\hline Roof, wall and road albedos & $0.10,0.20,0.10$ \\
\hline Roof, wall and road emissivities & $0.90,0.85,0.94$ \\
\hline Constant temperature inside building $(\mathrm{K})$ & 297.15 \\
\hline
\end{tabular}




\subsection{Performance Indicators}

Performance measures are widely used as summary measures of forecast quality. Several studies have analyzed the sensitivity of several performance measures to the displacement error, bias and event frequency $[48,49]$. Typical performance measures provide information on a single aspect of forecast quality, such as forecast accuracy. Accuracy is the degree of correspondence between the forecasts and observations [50] and is one of the many aspects of forecast quality that can be obtained from the joint distribution of forecasts and observations.

Several scores were used to verify the simulation results. Accumulated rainfall greater than a specific threshold was evaluated in terms of elements of the $2 \times 2$ contingency table (Table 5) along with a possible range of values [51]. As the contingency table needs observations and forecast values, the simulated results (ARPS) and satellite data (CMORHP, GMP and radar) were projected onto the same verification grid. Suitable thresholds $(q)$ were used to convert the satellite observed $\left(O_{r}\right)$ and forecast model $\left(M_{r}\right)$ rainfall into the binary fields $I_{\circ}$ and $I_{M}$ (Equation (1)). All pixels exceeding this threshold had a value of one and all others a value of zero. The 50th percentile (median) threshold $(q)$ was used to select the highest $50 \%$ (median) of observed and forecast accumulation for comparison, which removes the bias in rainfall amounts, and focuses on the spatial accuracy of the forecast.

$$
I_{\circ}=\left\{\begin{array}{ll}
1, & O_{r} \geq q \\
0, & O_{r} \leq q
\end{array} \quad I_{M}= \begin{cases}1, & M_{r} \geq q \\
0, & M_{r} \leq q\end{cases}\right.
$$

Table 5. Contingency table used to obtain the skill scores.

\begin{tabular}{ccccc}
\hline \multicolumn{5}{c}{ Observation (r) } \\
\hline & & Yes & No & Total \\
\hline Forecast (f) & Yes & Hit (a) & False alarm (b) & $\mathrm{a}+\mathrm{b}$ \\
& No & Miss (c) & Correct negative (d) & $\mathrm{c}+\mathrm{d}$ \\
Total & & $\mathrm{a}+\mathrm{c}$ & $\mathrm{b}+\mathrm{d}$ & $\mathrm{N}=\mathrm{a}+\mathrm{b}+\mathrm{c}+\mathrm{d}$ \\
\hline
\end{tabular}

For the present work we used: the probability of detection (POD), the threat score (TS), the equitable threat score (ETS), the true skill statistic (TSS), the bias-adjusted threat score (TSA) and the odds ratio skill score (ODSS) were used here, with the calculation of these performance indicators shown in Table 6.

Table 6. Definition of performance indicators.

\begin{tabular}{ccc}
\hline Score & Definition & Range \\
\hline Probability of detection & POD $=\frac{a}{a+c}$ & $0 \leq$ POD $\leq 1$ \\
\hline Threat score & TS $=\frac{a}{a+b+c}$ & $0 \leq \mathrm{TS} \leq 1$ \\
\hline Equitable threat score & ETS $=\frac{a-a_{\text {rand }}}{a+b+c-a_{\text {rand }}}$ & $-1 / 3 \leq \mathrm{ETS} \leq 1$ \\
& $a_{\text {rand }}=(a+b)(a+c)$ & \\
\hline True skill statistic & $\mathrm{TSS}=\frac{a}{a+c}-\frac{b}{b+d}$ & $-1 \leq \mathrm{TSS} \leq 1$ \\
\hline Bias-adjusted threat score & $\mathrm{TSA}=\frac{(a+c)^{1 / B}-c^{1 / B}}{(a+c)^{1 / B}+c^{1 / B}}$ & $-1 \leq \mathrm{TSA} \leq 1$ \\
& $B=\frac{a+b}{a+c}$ & \\
\hline Odds ratio skill score & ODDS $=\frac{a d-b c}{a d+b c}$ & $-1 \leq \mathrm{ODDS} \leq 1$ \\
\hline
\end{tabular}

\subsection{Bayesian Estimation Supersedes the t Test}

To evaluate the similarity between time series of model and radar rainfall estimates, we implemented the 'Bayesian estimation supersedes the $t$-test' method [52]. This method provides 
complete distributions of credible values for the group means and their difference, standard deviations and their difference and the effect size parameter, also the method is able to handle outliers. To accommodate outliers, the data were described with a $t$ distribution for both groups, which had heavier tails than the normal distribution. The method described the data with five parameters: a mean and standard deviation for each group and a normality parameter shared by the groups. For each possible combination of means and standard deviations, the effect size parameter (ES) was computed using the following:

$$
E S=\frac{\left(\mu_{1}-\mu_{2}\right)}{\left(\sigma_{1}^{2} / 2+\sigma_{2}^{2} / 2\right)^{1 / 2}}
$$

where the differences of the mean parameters $\left(\mu_{1}-\mu_{2}\right)$ describe the magnitude of the difference between the central tendency of the groups and the difference of the standard deviation parameters $\left(\sigma_{1}-\sigma_{2}\right)$. Thus, based on the results of Bayesian estimation, two distributions were more similar (different) if the effect size parameter was smaller (higher). The rainfall results of both experiments (tTEB and control) were compared with the rainfall values estimated by the weather radar of São Paulo as described below in Section 5.1.

\subsection{Synoptic Analysis for the Event of 12 January 2015}

Intense precipitation events with subsequent flash floods occurred in the MASP on 12 January 2015 [53], with a total of 35 flooded areas between 1800 UTC and 2100 UTC (15 and 18 LT, respectively). In general, these extreme precipitation events above the MASP can be associated with the interaction between the SBC and the UHIC. Figure 3a shows GFS surface wind and sea surface pressure fields over South America at 1800 UTC on 12 January 2015. Surface high pressure systems can be seen over the Pacific and Atlantic Oceans. The one over the Atlantic Ocean centered at $20^{\circ} \mathrm{W}$ and $25^{\circ} \mathrm{S}$ at $1200 \mathrm{UTC}$ moved westward at 18 UTC (15 LT). It induces NW and NE winds in MASP during the day, shifting to SW and SE under the SBC. A pressure trough is seen over the South-eastern Coast of Brazil associated to deep convection at 18 UTC (15 LT). In addition, a low pressure center of $1010 \mathrm{hPa}$ was observed to the east of the state of São Paulo.

Figure 4a shows a GOES-12 infrared image centered at the MASP for clear sky conditions at 1500 UTC. A remarkable UHI in MASP is depicted by the dark area. Figure $4 \mathrm{~b}$ shows a satellite image over the same region at 1800 UTC, where the cloudiness along the coast of the MASP is associated with the intense convective activity after the passage of the SBC. Figure $5 a, b$ show NCEP reanalysis and ARPS simulated $1000 \mathrm{hPa}$ winds for the $9 \mathrm{~km}$ domain at 1800 UTC. Both indicate a SBC moving inland towards the MASP.

Figure $3 b, c$ show the CAPE and convective inhibition (CIN), respectively, at $1000 \mathrm{hPa}$ for the south-eastern Brazil at 1800 UTC. The CAPE was between $1500 \mathrm{~J} \mathrm{~kg}^{-1}$ and $3000 \mathrm{~J} \mathrm{~kg}^{-1}$ and CIN was $150 \mathrm{~J} \mathrm{~kg}^{-1}$ above the MASP. They were consistent with deep convection development after the incoming the SBC (Figure $4 b$ ).

The incoming SBC over MASP is seen in Figure $5 a, b$ for NCAR reanalysis and for the ARPS $9 \mathrm{~km}$ domain at $1000 \mathrm{hPa}$, respectively. They both were consistent and indicated the ARPS simulated the SBC realistically. NCEP reanalysis has higher spatial resolution than GFS ones. Figure 5c shows $1000 \mathrm{hPa}$ moisture convergence along the coast of the South-eastern Brazil varying between $-0.9 \times 10^{-6}$ and $-1.5 \times 10^{-6} \mathrm{~g} \mathrm{~kg}^{-1} \mathrm{~s}^{-1}$. Thus, this pattern favored the development of deep convection over the MASP. Figure 5d shows $300 \mathrm{hPa}$ divergence over MASP close to $+1.5 \times 10^{-5} \mathrm{~s}^{-1}$. 

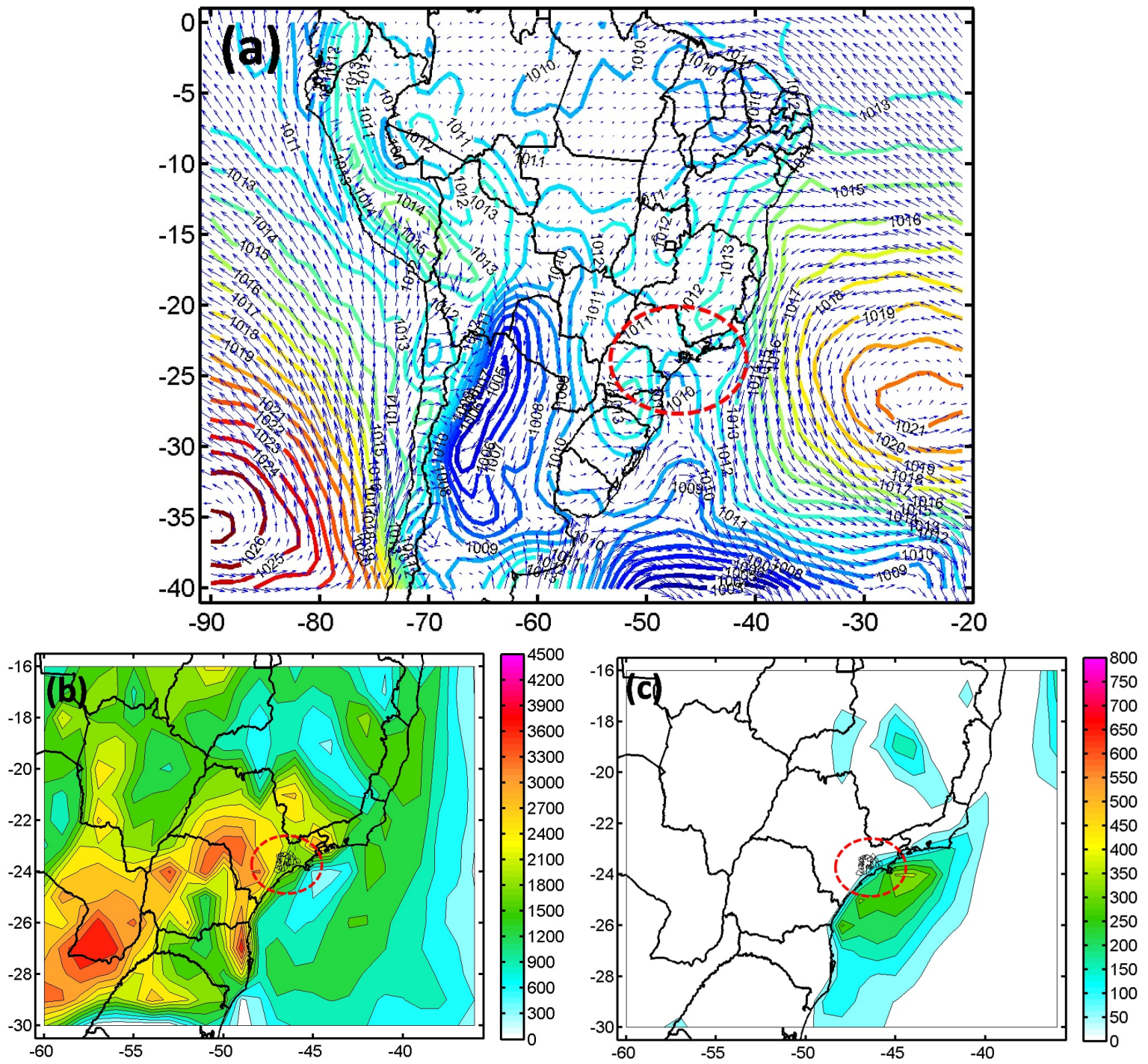

Figure 3. (a) Reduced pressure to sea level (hPa) and horizontal velocity fields $\left(\mathrm{m} \mathrm{s}^{-1}\right)$ from the Global Forecast System (GFS) model for 12 January 2015 at 18 UTC (15 LT). The isoline intervals are of $1 \mathrm{hPa}$. Cold colors indicate lower values and warm colors high values. Patterns of $(\mathbf{b})$ convective available potential energy (CAPE) $\left(\mathrm{J} \mathrm{kg}^{-1}\right)$ and (c) CIN $\left(\mathrm{J} \mathrm{kg}^{-1}\right)$ are derived from the GFS model for 12 January 2015 at 18 UTC (15 LT). Longitudes, latitudes and geopolitical contours are indicated. The red circle indicates the area around the MASP.
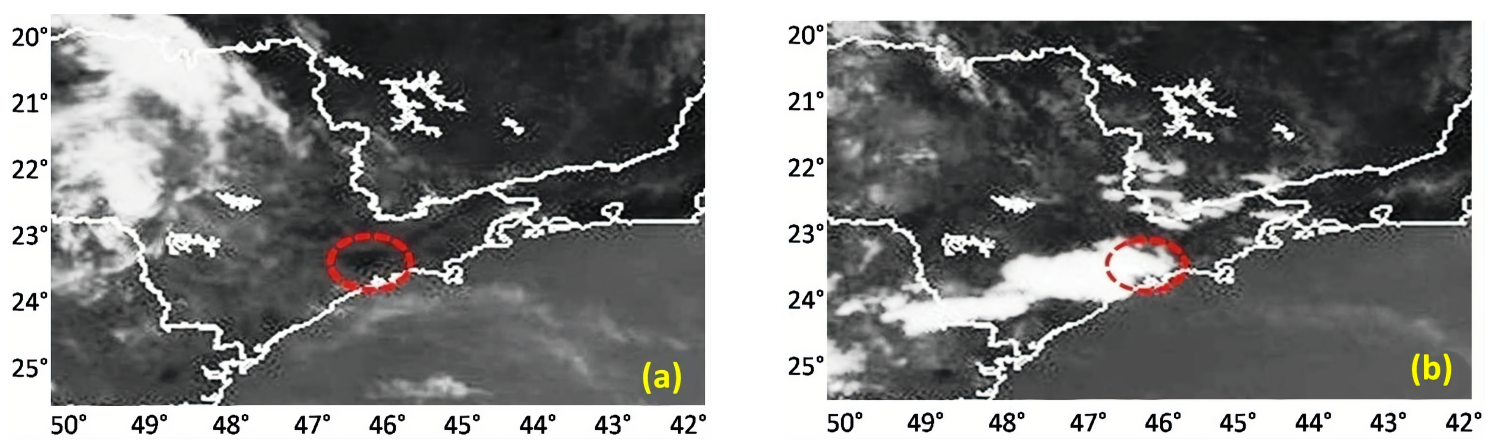

Figure 4. Images with high spatial resolution from the GOES-12 satellite for the infrared channel on 12 January 2015 at (a) 15 UTC (12 LT) and (b) 18 UTC (15 LT). The location of the MASP is highlighted with a red circle, where it is possible to observe the high temperatures at 1500 UTC. These figures were obtained from the web page of the CPTEC/INPE from Brazil (https://www.cptec.inpe.br/). 

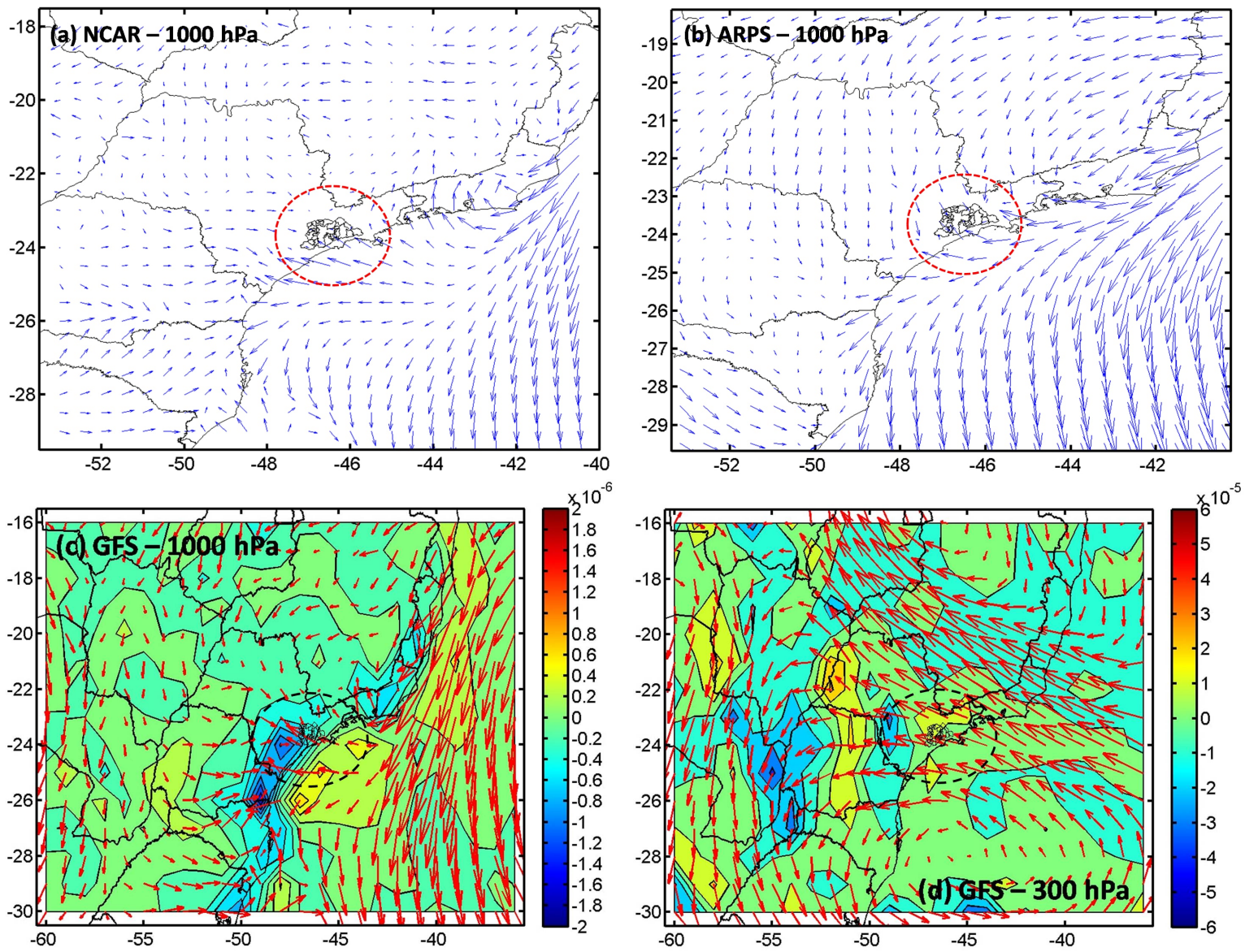

Figure 5. Comparison of (a) NCEP-NCAR reanalysis data (resolution $0.5^{\circ}$ ) and (b) ARPS model simulated flow circulation $\left(\mathrm{m} \mathrm{s}^{-1}\right.$ ) for the grid of $9 \mathrm{~km}$ and $1000 \mathrm{hPa}$. Moisture and mass divergence fluxes $\left(\mathrm{g} \mathrm{kg}^{-1} \mathrm{~s}^{-1}\right)$ from the GFS model for (c) $1000 \mathrm{hPa}$ and (d) $300 \mathrm{hPa}$ at $18 \mathrm{UTC}$ (15 LT) of 12 January 2015. Latitudes, longitudes and geopolitical contours are indicated. The circles indicate the area around the MASP.

\subsection{Datasets}

ARPS-tTEB simulations precipitation outputs were verified against SPWR precipitation estimation (Figure 6a) and rain gauge 10 min resolution measurements from the Center for Monitoring and Alerts of Natural Disasters (CEMADEN) located at 54 automatic pluviometric stations located on buildings of the city of São Paulo (Figure 6b). The SPWR is a $650 \mathrm{~kW}$ dual S-band Doppler system that surveys within a $240 \mathrm{~km}$ radius. Rainfall rates are estimated at $2 \times 2 \mathrm{~km}^{2}$ every $5 \mathrm{~min}$.

For the present contribution, were used the Climate Prediction Center (CPC) morphing technique $(\mathrm{CMORPH})$ precipitation estimates, that use low orbiter satellite microwave observations obtained entirely from geostationary satellite infrared data at $0.25^{\circ}$ resolution every $3 \mathrm{~h}$, as well as the Global Precipitation Measurement (GPM) mission, that estimates precipitation every half-hour at $0.1^{\circ}$ resolution between $65^{\circ} \mathrm{N}$ to $65^{\circ} \mathrm{S}$. The spatial-temporal precipitation distribution of all rain gauge measurements and remote sensing estimates for 12 January 2015 are shown in Section 5.1. The third generation $0.5^{\circ}$ reanalysis of the climate forecast system reanalysis (CFSR) by NCEP was used to verify ARPS wind and moisture simulations. 

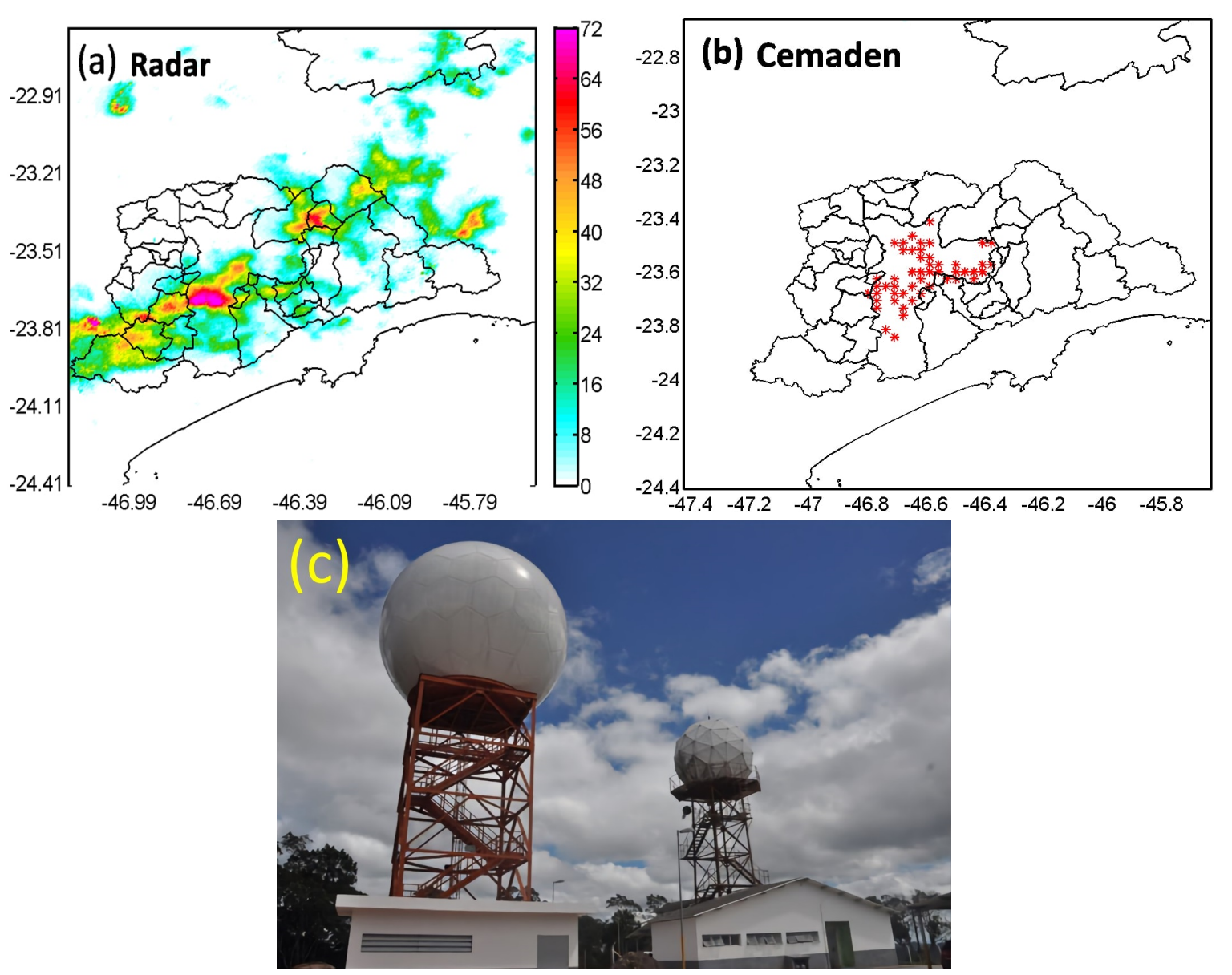

Figure 6. (a) The spatial distribution of the accumulated precipitation ( $\mathrm{mm}$ ) estimated from the weather radar of São Paulo between 17 UTC (14 LT) and 21 UTC (18 LT). (b) Geographic locations of automatic pluviometric stations maintained by Center for Monitoring and Alerts of Natural Disasters (CEMADEN) in the MASP [54]. (c) The São Paulo weather radar (SPWR) located at $23^{\circ} 36^{\prime} 00^{\prime \prime}$ S, $45^{\circ} 58^{\prime} 20^{\prime \prime} \mathrm{W}$ and $916 \mathrm{~m}$. The radar was manufactured by McGill University of Canada and is installed in the Ponte Nova dam located at the headwaters of the Tietê River.

\section{Analysis of the Results}

\subsection{Rainfall on 12 January 2015}

The SPWR precipitation accumulation field between 1700 UTC and 2100 UTC on 12 January 2015 is shown in Figure 6a. Figure 7a,b show area median and 75\% quantile every 5 min precipitation accumulation over ARPS 3-km domain (Figure 6a) for SPWR, tTEB and control runs. Both ARPS simulated precipitation results agreed with the SPWR precipitation estimates. A maximum of $12 \mathrm{~mm}$ for median and $18 \mathrm{~mm}$ for $75 \%$ quantile occurred at 1830 UTC. Further discussion will be shown in Section 5.3.3. Figure 7c shows the time evolution of the rain gauge network (Figure 6b) precipitation average and respective tTEB and control precipitation for grid points with rain gauges. Again, simulated and measurements agree in phase and amplitude with a maximum of $200 \mathrm{~mm}$ at 1830 UTC. Rainfall rates were higher for control than TTEB run and rain gauge measurements since rainfall rates were higher in the control run over the SE where more rain gauges were available than over NE of the MASP (Figure 7b). 

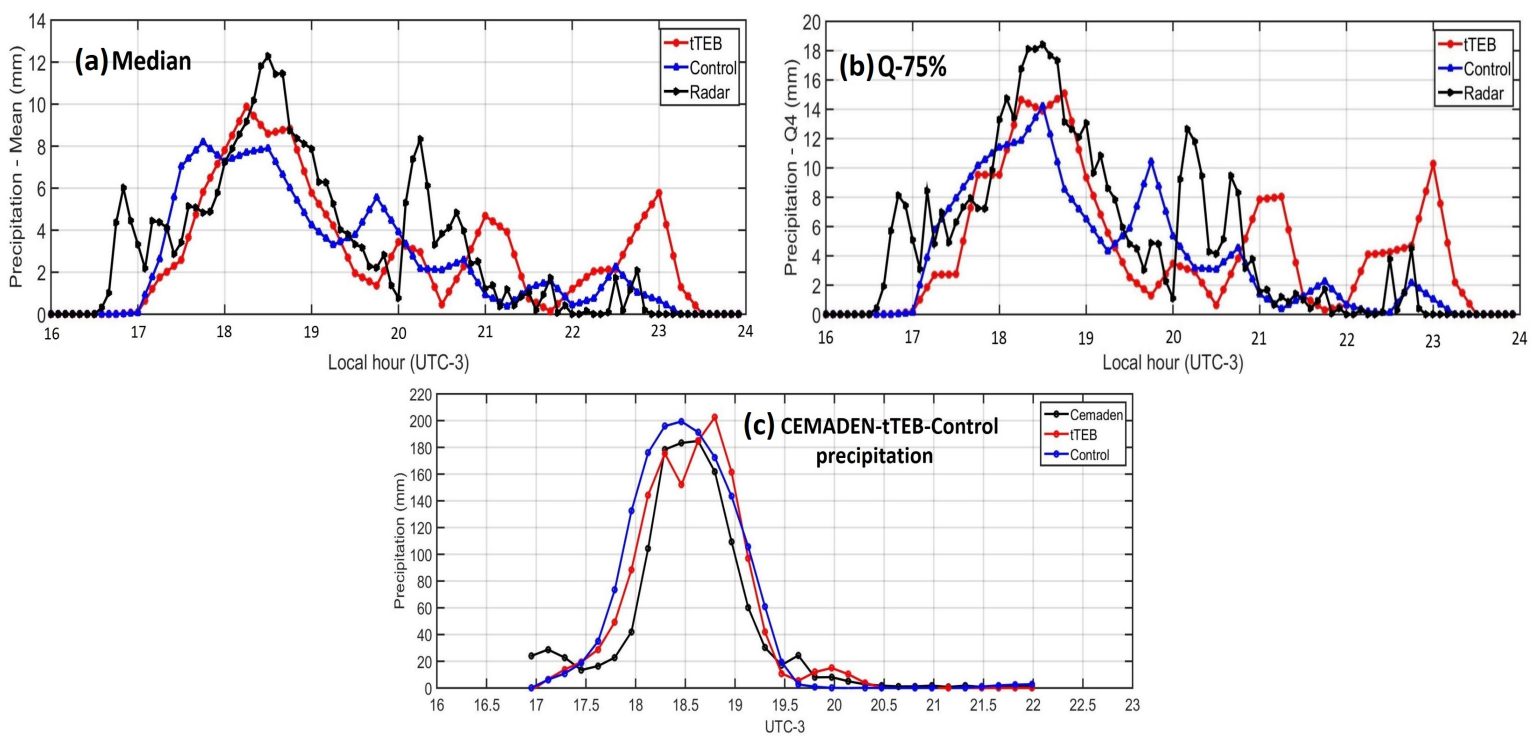

Figure 7. (a) Time series of mean precipitation $(\mathrm{mm})$ for the region showed in Figure 6a, obtained from the control and tTEB experiments and estimated by radar. (b) Time series of the $75 \%$ quantile precipitation $(\mathrm{mm})$ for the region showed in Figure 6a obtained from the control and tTEB experiments and estimated from the radar data. (c) Time series of accumulated precipitation ( $\mathrm{mm}$ ) obtained from the control and tTEB experiments and measured by the pluviometric stations shown in Figure 6b.

Figure $8 \mathrm{a}, \mathrm{b}$ show precipitation accumulation fields between 1700 UTC and 2100 UTC on 12 January 2015 obtained with the CMORPH and GPM systems, respectively. The GPM precipitation accumulation $(36 \mathrm{~mm})$ is twice the CMORPH $(18 \mathrm{~mm})$ one over MASP though with spatial phases very similar. Similarly, Figure $8 \mathrm{c}-\mathrm{e}$ show precipitation accumulation for tTEB and control run $\mathrm{s}$ and the difference fields (tTEB-control). Both indicate similar precipitation accumulation maxima of $48 \mathrm{~mm}$ over the MASP. Both runs indicate more convective cells over MASP but with significant differences between them caused by moisture advection and more unstable air induced by the UHI on tTEB experiment as temperature gradient increases in SE-NW direction. So, the greater acceleration of the SBC, the greater convergence and lifting to trigger deep convection northward of the MASP.
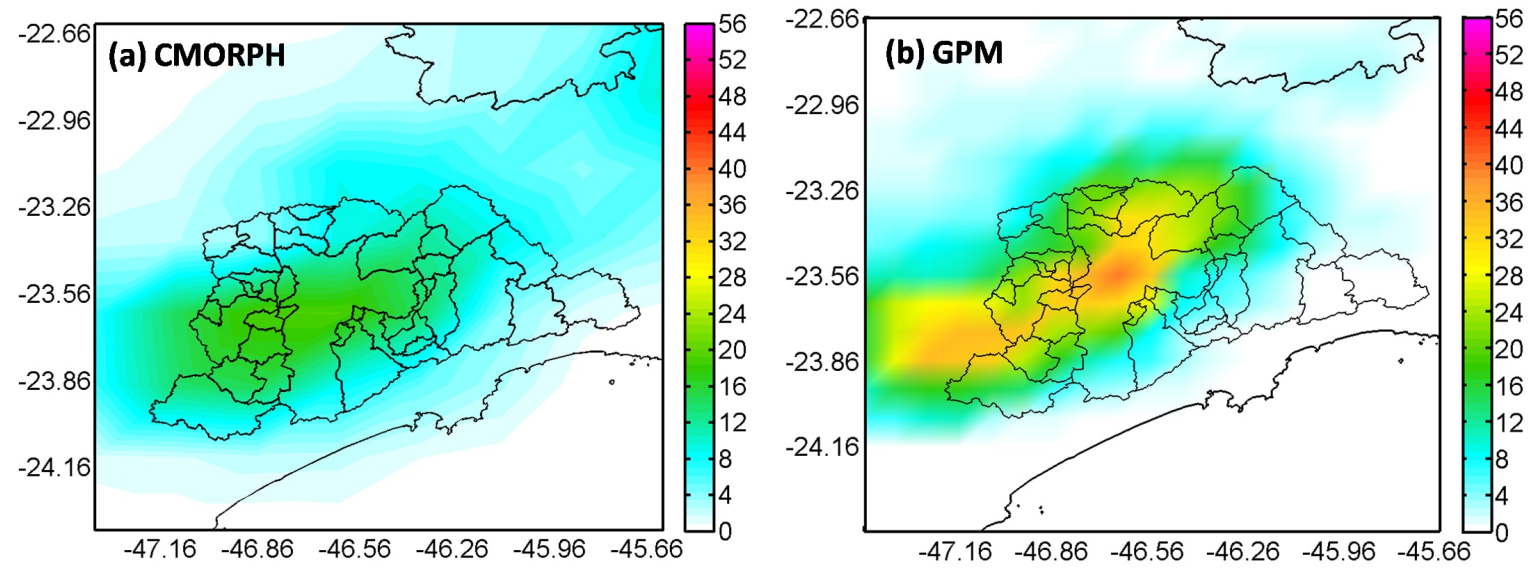

Figure 8. Cont. 


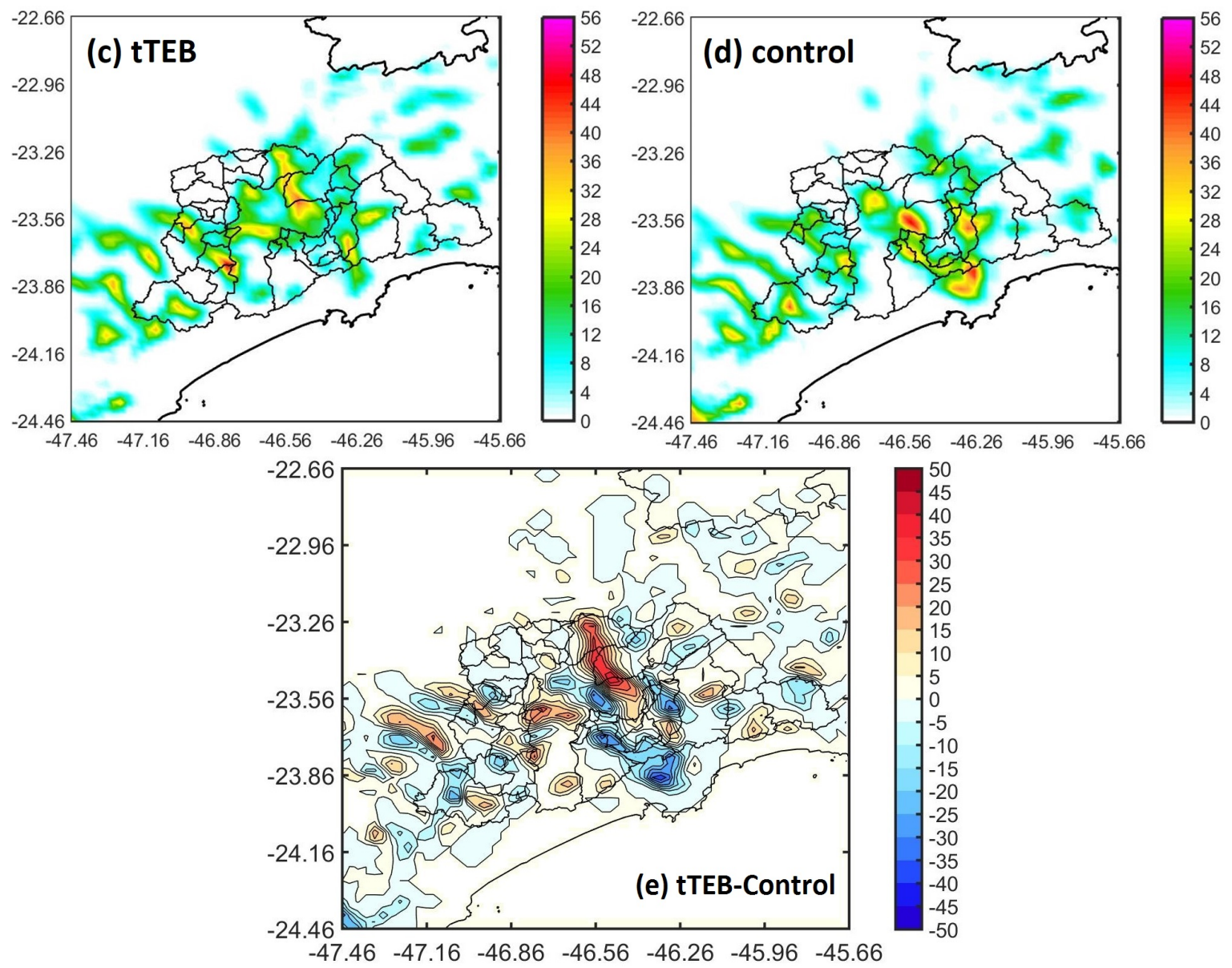

Figure 8. Spatial distribution of accumulated precipitation rate $\left(\mathrm{mm} \mathrm{h}^{-1}\right)$ between 17 UTC (14 LT) and 21 UTC (18 LT) estimated by (a) CMORPH: Climate Prediction Center (CPC) morphing technique (resolution: $0.25^{\circ}$ ), (b) GPM: global precipitation measurement (resolution: $0.1^{\circ}$ ), (c) tTEB experiment (resolution: $3 \mathrm{~km}$ ), (d) Control experiment (resolution: $3 \mathrm{~km}$ ) and (e) differences between tTEB and control experiments.

\subsection{ARPS-tTEB Verifications}

The difference between rain gauge measurements from CEMADEN and precipitation from tTEB and control runs (Figure 7c) was evaluated using the statistics of Table 7. For tTEB (control) experiment, the slope of the best fit regression line was 1.07 (1.14), the mean absolute error (MAE) is -5.20 (-9.46), the percent bias (PBIAS) was 12.78 (23.26) and the root mean square error was 20.68 (27.24). The PBIAS indicates an overestimation of the model relative to measurements. In general, these statistics indicate tTEB performed better than the control run. The precipitation fields in Figure 8c, d for the tTEB and control runs, respectively, show phase displacement. The control run precipitation field was not well simulated since it was concentrated over the SE and outside of the MASP. On the other hand, the tTEB precipitation field is concentrated above and downwind of the MASP and higher between $8 \mathrm{~mm} \mathrm{~h}^{-1}$ and $40 \mathrm{~mm} \mathrm{~h}^{-1}$ (Figure 8e).

Table 7. Statistical quantities to evaluate the performance of rainfall estimates by tTEB and control experiments against observed rainfall of pluviometric stations of Center for Monitoring and Alerts of Natural Disasters (CEMADEN).

\begin{tabular}{cccccc}
\hline Scores & Slope & y-Inter & MAE & PBIAS & RMSE \\
\hline tTEB & 1.07 & $-3.3 \times 10^{-4}$ & -5.20 & 12.78 & 20.68 \\
Control & 1.14 & $-4.9 \times 10^{-4}$ & -9.46 & 23.26 & 27.24 \\
\hline
\end{tabular}


Further verification was carried out with CMORPH and GPM precipitation estimates with spatial indicators described in Section 6 by comparing precipitation estimates from CMORPH (Figure 8a) and GPM (Figure 8b) with precipitation estimates from the tTEB (Figure 8c) and control (Figure 8d) runs between 1700 UTC and 2100 UTC on 12 January 2015. All performance measures improved by $8 \%$ with tTEB (Table 8). This slight improvement was due to simulated convective cells formed NW of the MASP with the TTEB run (Figure 8c) with better phase and amplitude compared to CMORPH (Figure 8a), GPM (Figure 8b) and the SPRW (Figure 6a). On the contrary, the control run generated convective cells towards SE of the MASP (Figure 8d).

Table 8. Performance measures described in Section 6 for the rainfall results of the tTEB, control experiments, rainfall estimates of satellites (Global Precipitation Measurement (GPM) and CMORPH) and rainfall estimates the weather radar.

\begin{tabular}{ccccccc}
\hline & \multicolumn{2}{c}{ GPM } & \multicolumn{2}{c}{ CMORPH } & \multicolumn{2}{c}{ RADAR } \\
\hline & tTEB & Control & tTEB & Control & tTEB & Control \\
\hline ETS & 0.35 & 0.32 & 0.32 & 0.28 & 0.30 & 0.28 \\
TSS & 0.50 & 0.47 & 0.46 & 0.44 & 0.44 & 0.42 \\
POD & 0.58 & 0.53 & 0.50 & 0.47 & 0.48 & 0.45 \\
TS & 0.40 & 0.36 & 0.38 & 0.34 & 0.35 & 0.32 \\
TSA & 0.42 & 0.37 & 0.36 & 0.33 & 0.37 & 0.35 \\
ODDS & 0.89 & 0.84 & 0.90 & 0.87 & 0.85 & 0.82 \\
\hline
\end{tabular}

Bayesian estimation provides rich and complete information about the joint distribution of credible parameter values, including the means, standard deviations, effect size, and normality between data from two groups. This method minimizes extraneous influences on the data contaminated by random variability. Bayesian estimation can accept the null value by using a decision procedure involving the high density interval (HDI) and provides precise power analysis for multiple goals of research [52]. For these reasons, ARPS-tTEB precipitation simulations were verified against the SPWR rainfall estimates between 1600 UTC on 12 January to 0000 UTC on 13 January 2015. A Bayesian approach described in Section 4.4 was used to verify the time series of mean precipitation. Figure $9 \mathrm{a}, \mathrm{b}$ show histograms of effect size parameter (Equation (2)) between the median precipitation simulated by the tTEB and control runs compared to the ones of SPWR, respectively. The effect size parameter was -0.006 for the tTEB run on average with a $95 \%$ HDI from -0.371 to 0.240 . In contrast, for the control run, it was -0.181 , on average about three fold higher than the previous case with a 95\% HDI from -0.496 to 0.118 . Figure $9 \mathrm{c}, \mathrm{d}$ show similar histograms but for the $75 \%$ quantile precipitation results. The effect size parameter was -0.115 for the tTEB run on average with a $95 \%$ HDI from -0.423 to 0.197 while for the control run it was -0.255 on average about twice that of the previous case with a $95 \%$ HDI from -0.571 to 0.043 . Consequently, for the median and $75 \%$ quantile precipitation time series, the tTEB run shows lower effect size parameter than the control run and, therefore, greater similarity with SPWR precipitation estimates. 

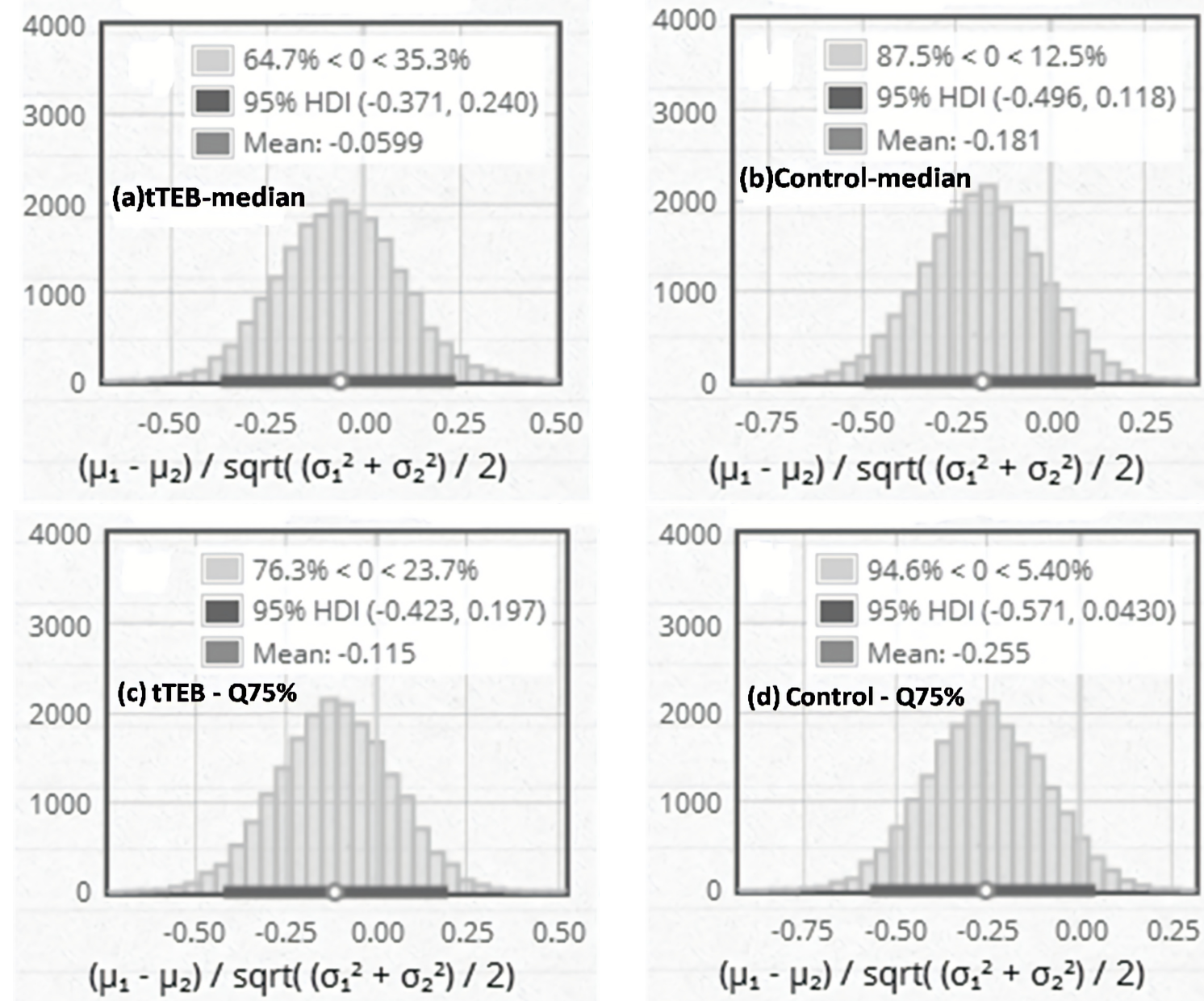

Figure 9. Histogram distribution of effect size parameter (Equation (2)) between median and quantile $75 \%$ rainfall results of $(\mathbf{a}, \mathbf{c})$ tTEB and $(\mathbf{b}, \mathbf{d})$ control experiments with median and quantile $75 \%$ rainfall estimates of weather radar. The two data groups are shown in Figure $7 a, b$, respectively. These figures were made using the version online of the Bayesian Estimation Supersedes the t-test (BEST) http:/ / sumsar.net/best_online/ providing the rainfall data. This page was made by Rasmus Baath, at Lund University Cognitive Science, Sweden.

\subsection{Impact of the Couple System ARPS-tTEB}

In this section, we discuss the impact the tTEB scheme on ARPS variables. The ARPS-tTEB system is able to represent thermal and mechanical properties of the urban environment of the MASP to induce convective processes.

\subsubsection{Temperature and Energy Fluxes}

In general, a valid simulation of surface air temperature is important in view of the well-known dependency of lower boundary layer stability on the heat flux from the surface. For the urban area of the MASP, [55] showed maximum UHI between 1700 UTC and 1900 UTC varying between $2.6^{\circ} \mathrm{C}$ in July and $5.5^{\circ} \mathrm{C}$ in September. A recent contribution [45], estimated monthly long-term (2001-2014) surface UHI intensities for the urban area of the MASP using remote sensing data obtained from MODIS sensor. They found that in January, the mean surface UHI intensity is close to $10^{\circ} \mathrm{C}$. The simulation results confirm this magnitude of the surface UHI for the city of São Paulo, as it is observed in Figure 10, which shows the mean soil surface temperature between 0000 UTC of 12 January 2015 to 0000 UTC of 13 January 2015 ( $24 \mathrm{~h}$ ). The differences of surface temperature for the urban area between the tTEB and control experiments reached values around to $6{ }^{\circ} \mathrm{C}$. 
An urban cooling effect was observed in dispersed (low-density) urban areas along to the coast of the MASP with magnitudes close to $-5^{\circ} \mathrm{C}$. This effect could be explained because during the day, lower density urban forms have higher albedos given reflections from roads were not intercepted by adjacent walls and irradiance is distributed over larger surfaces in street canyons when compared to open sites. In contrast, the semi-desert canopy was exposed to direct solar irradiance continuously along the day and experienced a substantial rise in temperature [8]. Furthermore, the sea-breeze advected relatively cold and humid air from the sea above the urbanized coastal plain until the moment that its cooling effect exceeded the radiative warming effect.

The net result was urban cooling on the coastal urban area in the afternoon, while the urban area of the MASP, located $50 \mathrm{~km}$ above the plateau and away from the coast, was still warmer than the vegetated area around it, despite the late entrance of the sea-breeze inland. This urban cooling effect could be verified with in-situ surface measurements of wind and temperature along the coast of the MASP to evaluate the introducing observed sky view factor (SVF) in numerical models to reproduce surface wind and temperature when subjected under different SVF specified for different aspect-ratio parameters of the urban canopy (Table 3) [56].
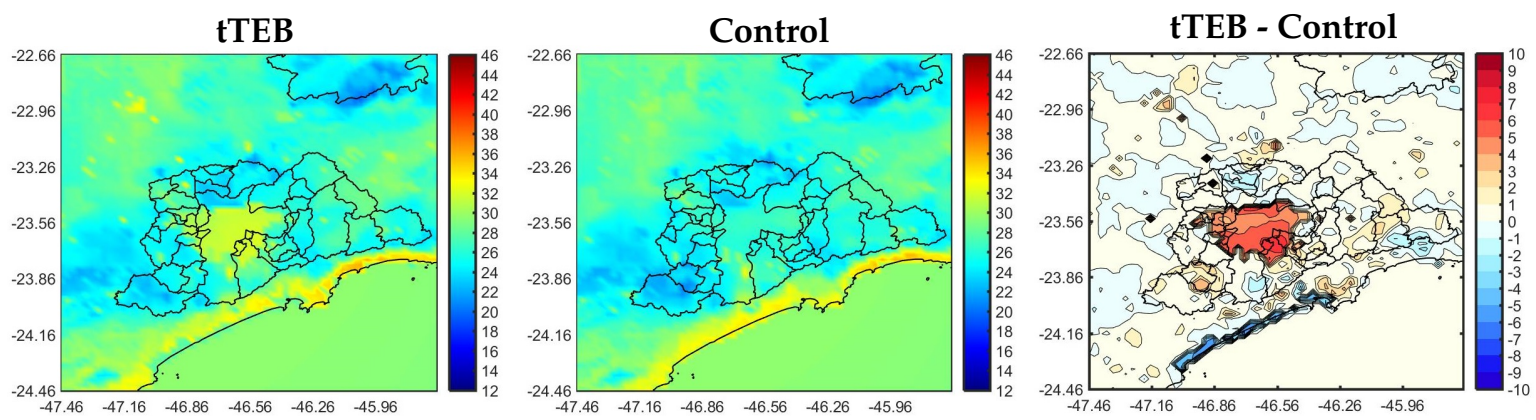

Figure 10. Mean soil surface temperature $\left({ }^{\circ} \mathrm{C}\right)$ between 00 UTC (21 LT) of 12 January 2015 to 00 UTC (21 LT) of 13 January 2015. The figure shows the results of the tTEB experiment (first column), the control experiment (second column) and the differences between both experiments (third column).

The UHI was adequately simulated with the system ARPS-tTEB for the MASP. Its effect was significant both during the day and night (Figure 10). Figure 11 (first row) shows $10 \mathrm{~m}$ air temperature at 0600 UTC of 12 January 2015 for the two experiments (tTEB and control) and their difference. At this time, temperature differences were $3{ }^{\circ} \mathrm{C}$ within the urban area of the MASP. The wind field indicated a land-breeze feature channeled by the topography. The land-breeze was more intense for the control run given a greater temperature difference between sea and the semi-desert canopy.

Later, at 1830 UTC, the surface air temperature and sea-breeze front around the MASP were modified by the cooling effect of rainfall and gust fronts associated to convective cells (Figure 11-second row). As was mentioned above, the UHI tended to speed up the sea-breeze front inland causing convergence zones northward in the TTEB run and convergence southward along the coast in the control run (Figure 8e). Thus, negative temperature differences were NW and NE and positive ones were SE of the MASP. The UHI in the urban area of the MASP induced temperature differences up to $5{ }^{\circ} \mathrm{C}$. 
The vertical extent and impact of the UHI into the boundary layer over MASP is analyzed in Figure 12 (first row). It shows vertical cross sections of mean air temperature between $46.9^{\circ} \mathrm{W}$ and $46.72^{\circ} \mathrm{W}$ at 0600 UTC on 12 January 2015 for the tTEB and control runs and the temperature difference cross section field between tTEB and control. The UHI effect was more significant above and downwind of the city from $23.49^{\circ} \mathrm{S}$ to $23.76^{\circ} \mathrm{S}$. Vertically, the higher air-temperature difference was $4{ }^{\circ} \mathrm{C}$ close to the surface, with lower temperature differences around $1^{\circ} \mathrm{C}$ up to $600 \mathrm{~m}$ above the ground, and beyond this altitude the warming effect essentially disappeared. At 1830 UTC (Figure 12 second row), the cooling effect of the rainfall and gust fronts of the convective cells modified the patterns of temperature above the urban area of the MASP. However, the influence of the UHI was still observed upwind and downwind of the MASP from $23.4^{\circ} \mathrm{S}$ to $24.0^{\circ} \mathrm{S}$. Vertically, the higher air-temperature difference close to $4{ }^{\circ} \mathrm{C}$ is present up $100 \mathrm{~m}$ above the ground. Lower temperature differences of $1{ }^{\circ} \mathrm{C}$ extend to $700 \mathrm{~m}$ high.

Solar irradiance was converted into a higher rate of sensible heat flux over the urban area of the MASP than in its dryland and cropland outskirts given the lower specific heat capacity and surface albedo. Latent heat flux was much lower since it was drier and with low evapotranspiration [57]. In general, the horizontal gradient of sensible and latent heat fluxes was caused by soil moisture gradients [58]. Figure 13 shows the spatial distribution of the sensible heat flux at the surface for 12 January 2015 at 0600 UTC (first row) and 1830 UTC (second row) for the tTEB and control runs. They agree with the surface air temperature field discussed above. The sensible heat flux increases $80 \mathrm{~W} \mathrm{~m}^{-2}$ at 0600 UTC in the tTEB run since its dissipation is slower than in the semi-desert canopy of the control run. This lagging on sensible heat flux was positive until after sunset and allowed the atmospheric warming by turbulent heat transport [23]. Differences in sensible heat flux between tTEB and control runs increases to $200 \mathrm{~W} \mathrm{~m}^{-2}$ at 1830 UTC due to rainfall and downdraft cooling effects.

High spatial variability of latent heat fluxes resulted from land surface and atmosphere interaction. Figure 14 shows the spatial distribution of surface latent heat flux at the surface at 0600 UTC (first row) and 1830 UTC (second row) on 12 January 2015 for tTEB and control runs and their differences. At 0600 UTC, the latent heat flux was slightly lower for the urban surface (tTEB run) in comparison with the semi-desert canopy (control experiment) up to values close to $30 \mathrm{~W} \mathrm{~m}^{-2}$ due to the reduced moisture availability and the lack of evapotranspiration. At $1830 \mathrm{UTC}$, during the period of intense rainfall, the differences of latent heat flux inside the urban environment can reach values of $300 \mathrm{~W} \mathrm{~m}^{-2}$. As expected, the larger differences occurred over the urban area of the MASP during the rainfall occurrence because urban surface drainage reduces the evaporation and so the latent heat flux. 


\section{tTEB}
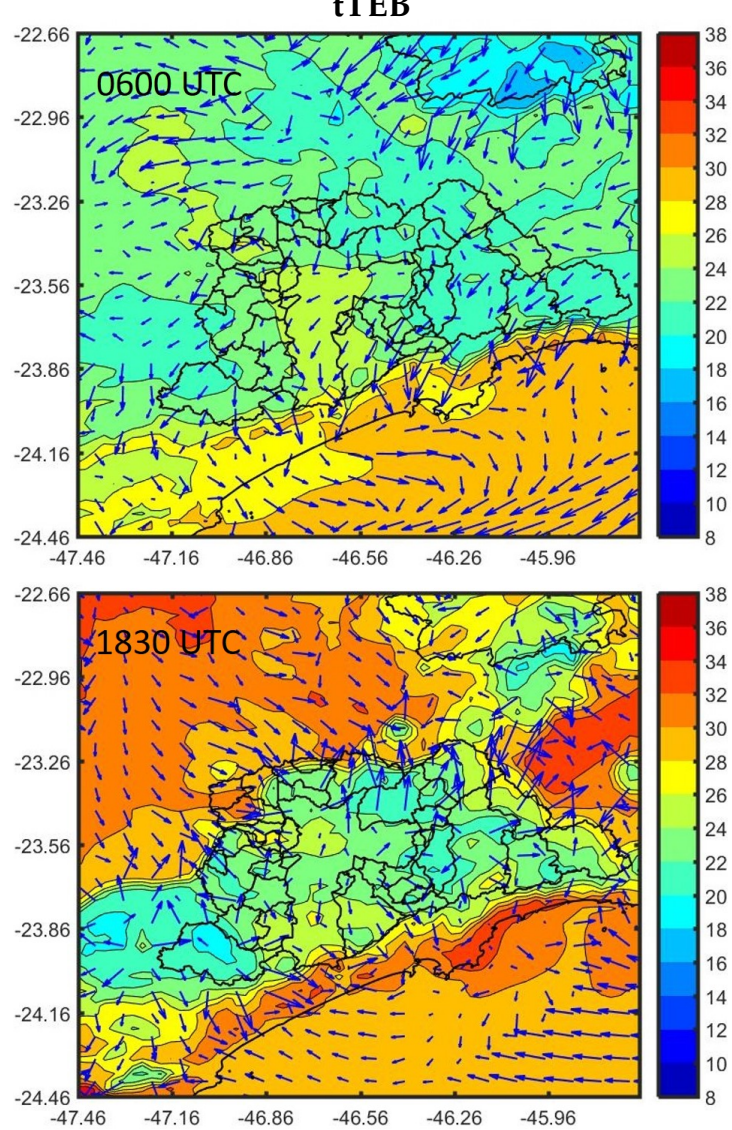

Control
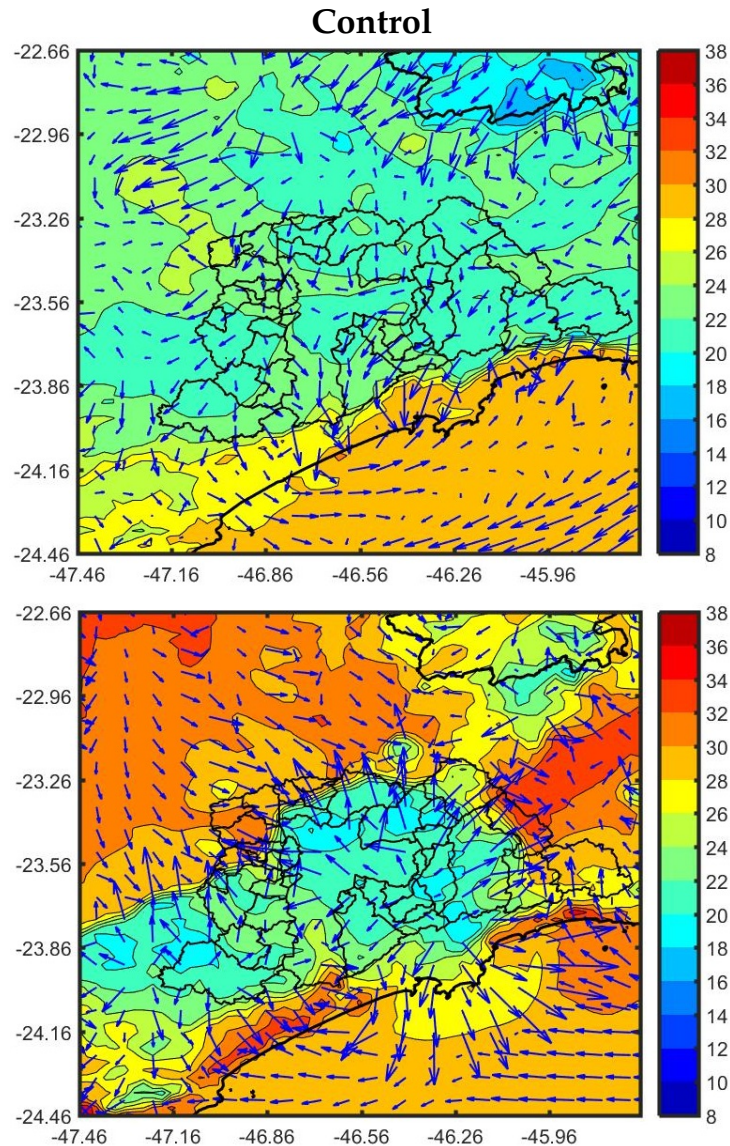

tTEB - Control
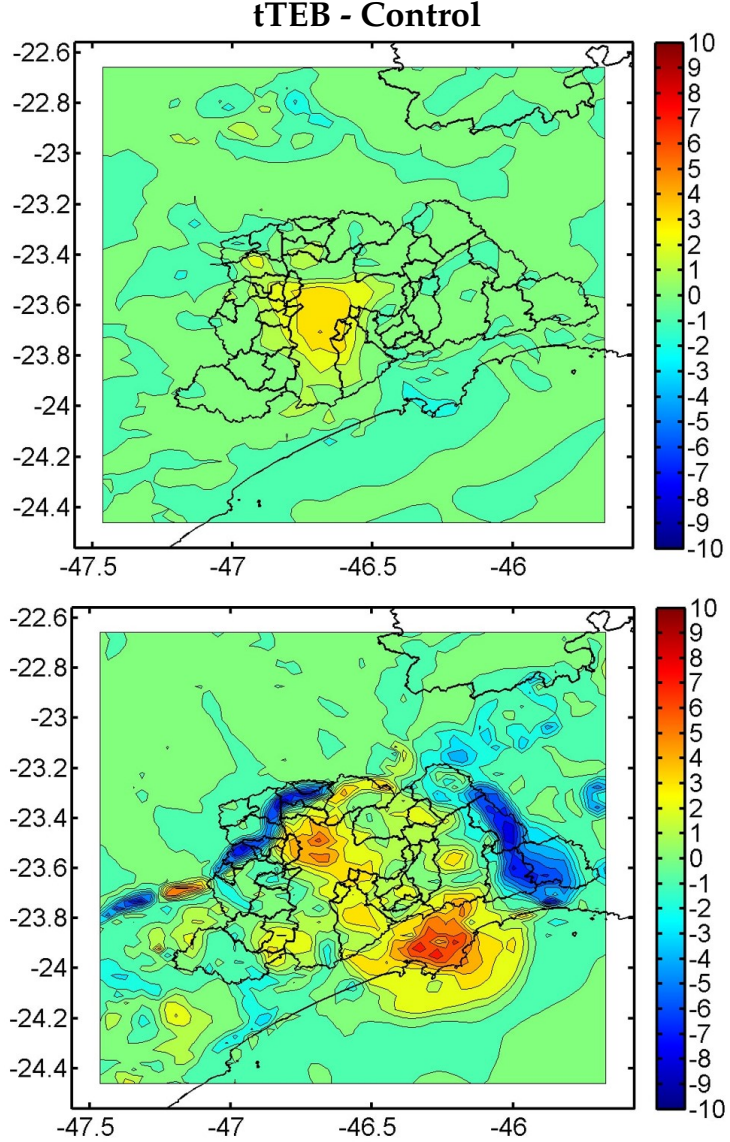

Figure 11. Vertical cross section of mean air temperature $\left({ }^{\circ} \mathrm{C}\right)$ between $46.90^{\circ} \mathrm{W}$ to $46.42^{\circ} \mathrm{W}$ at $06 \mathrm{UTC}(03 \mathrm{LT})$ (first row), $1830 \mathrm{UTC}(1530 \mathrm{LT})$ (second row) along the latitude. The figure shows the results of the tTEB experiment (first column), the control experiment (second column) and the differences between both experiments (third column). Triangles indicate the extension of urban canopy of the MASP. 
tTEB
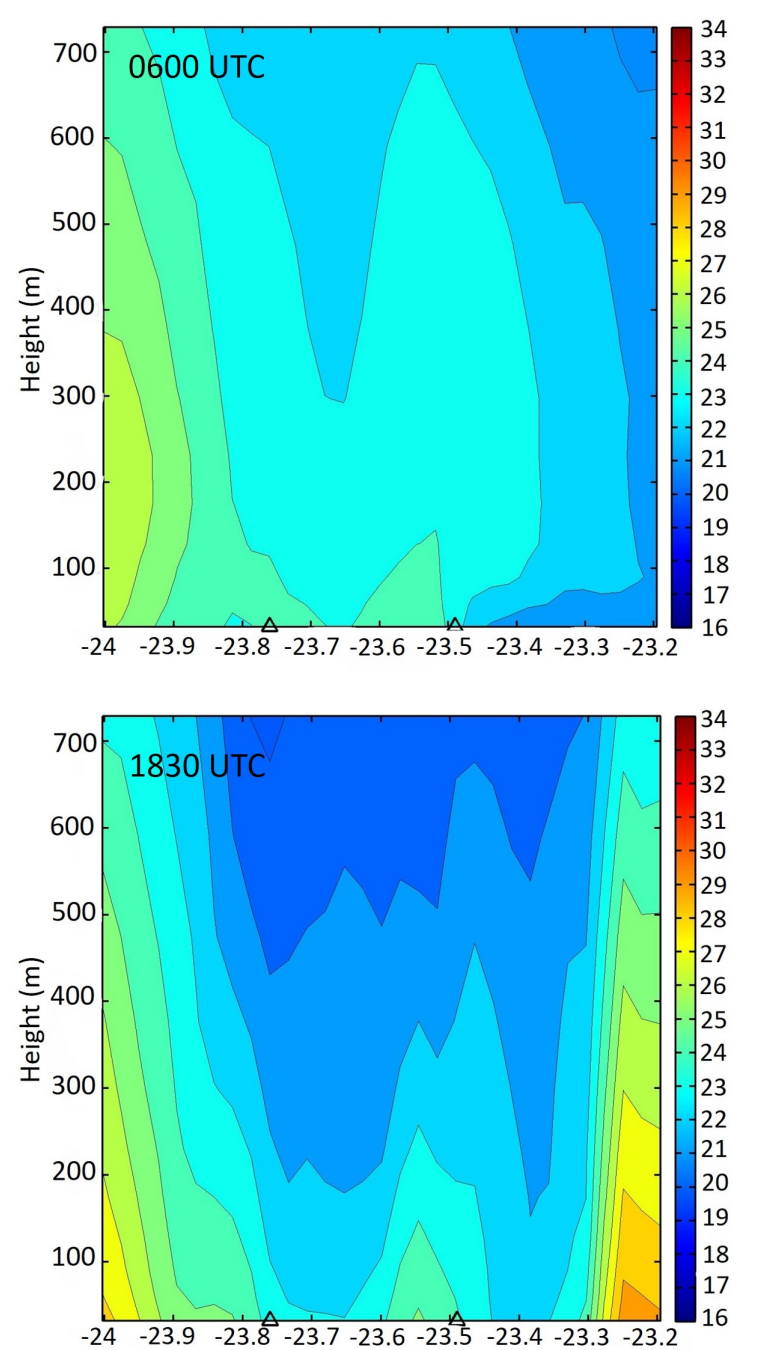

Control
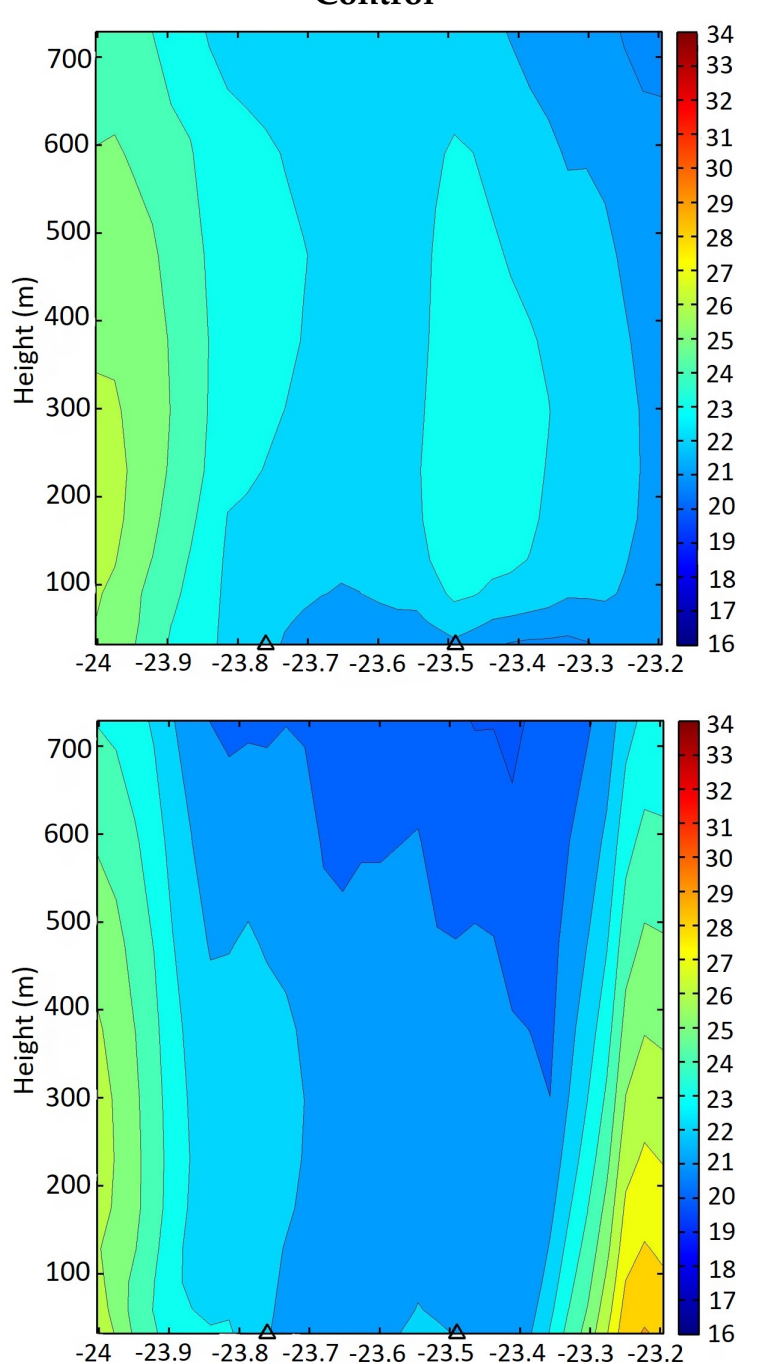

tTEB - Control
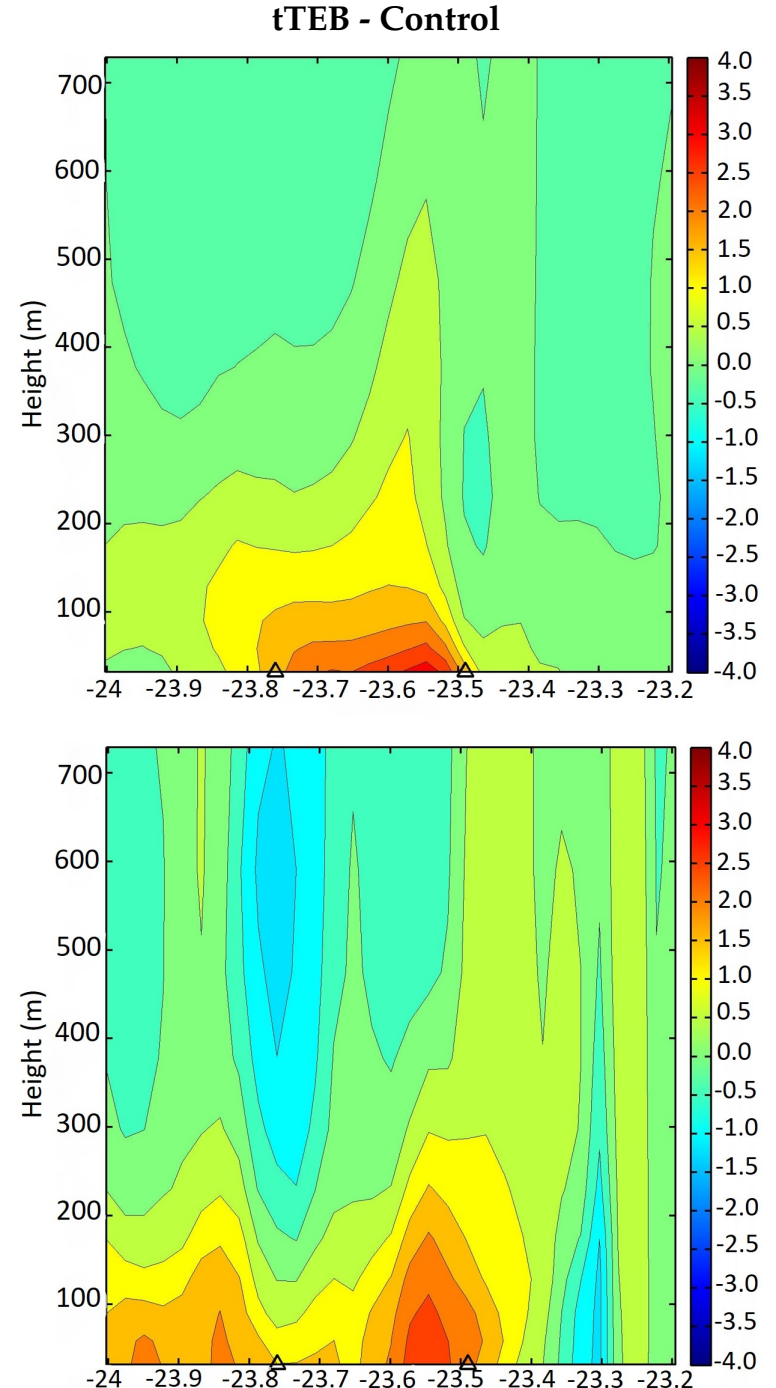

Figure 12. Vertical cross section of mean air temperature $\left({ }^{\circ} \mathrm{C}\right.$ ) between $46.90^{\circ} \mathrm{W}$ to $46.42^{\circ} \mathrm{W}$ at $06 \mathrm{UTC}(03 \mathrm{LT})$ (first row), $1830 \mathrm{UTC}(1530 \mathrm{LT})$ (second row) along the latitude. The figure shows the results of the tTEB experiment (first column), the control experiment (second column) and the differences between both experiments (third column). Triangles indicate the extension of urban canopy of the MASP. 

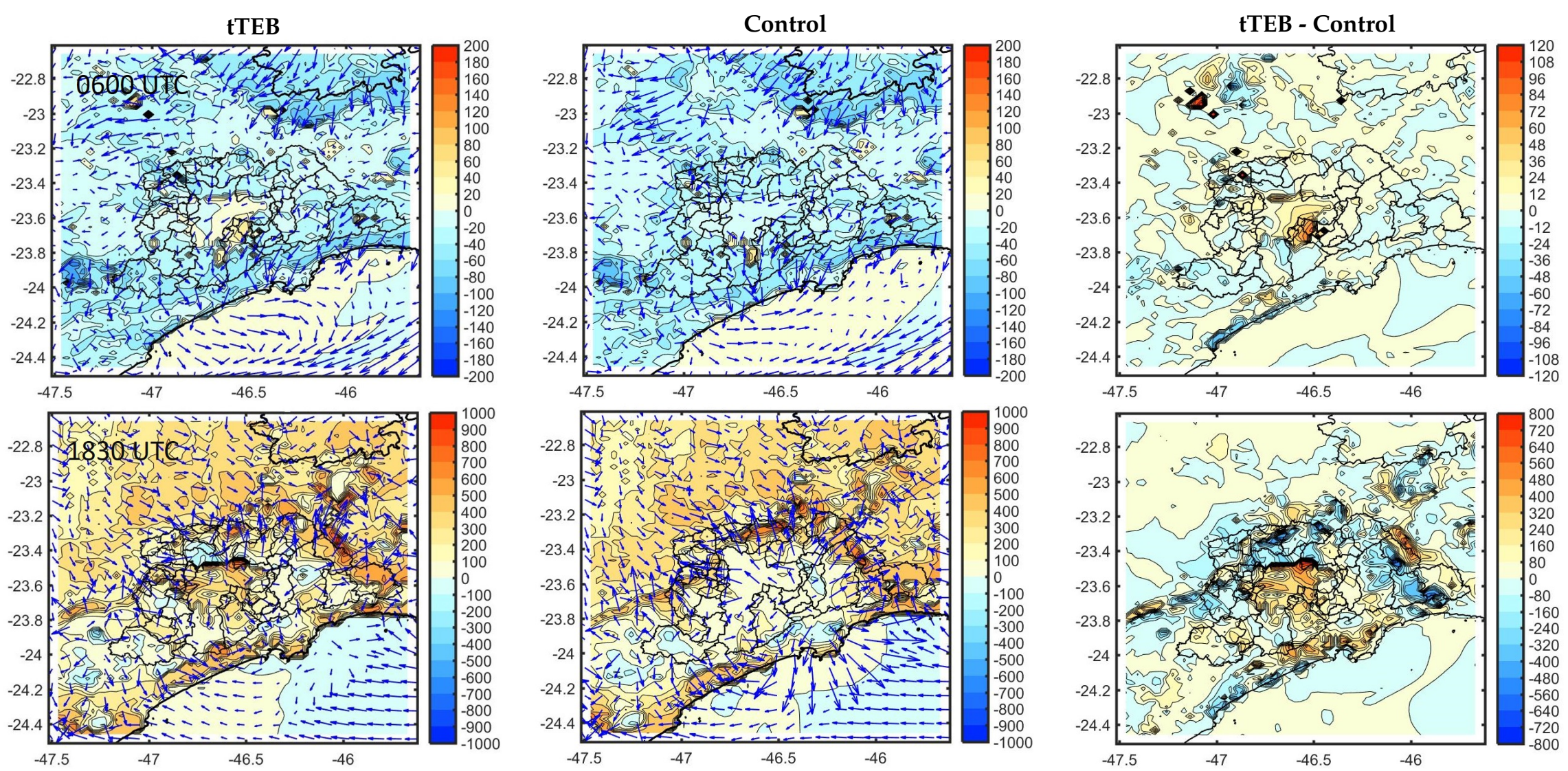

Figure 13. Horizontal pattern of sensible heat flux ( $\mathrm{W} \mathrm{m}^{-2}$ ) at the surface for 12 January 2015 at 06 UTC (03 LT) (first row) and 1830 UTC (1530 LT) (second row).

The figure shows the results of the tTEB experiment (first column), control experiment (second column) and the differences between both experiments (third column). 

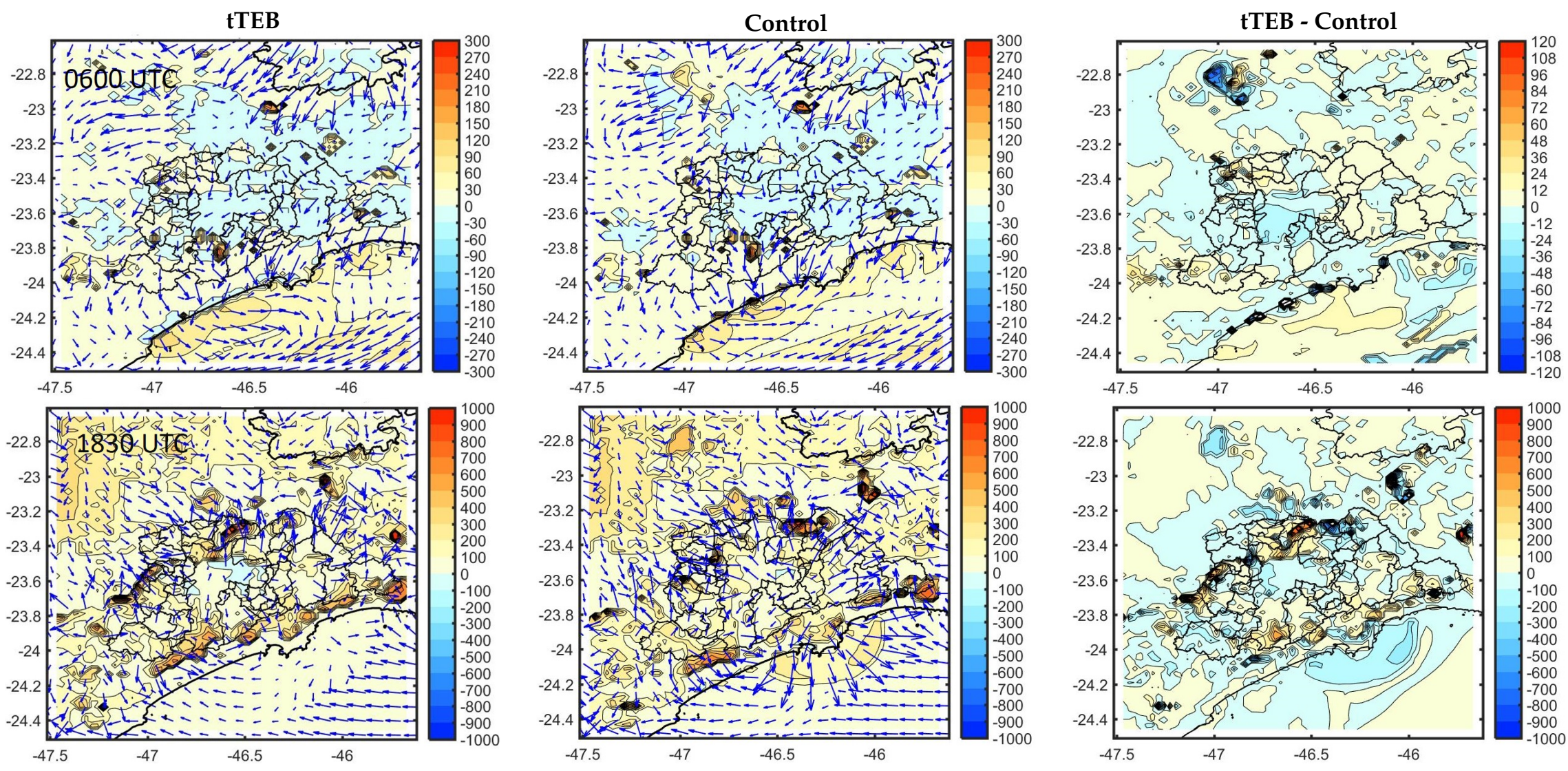

Figure 14. Horizontal pattern of latent heat flux $\left(\mathrm{W} \mathrm{m}^{-2}\right.$ ) at the surface for 12 January 2015 at 06 UTC (03 LT) (first row) and 1830 UTC (1530 LT) (second row). The figure shows the results of the tTEB experiment (first column), control experiment (second column) and the differences between both experiments (third column). 


\subsubsection{Flow Properties and Convergence}

The effects of explicit urban environment representation on mountain valley and SBC above the MASP using ARPS-tTEB system have been studied [23]. Diurnal SBC and land nocturnal circulation effects caused by the UHI in the MASP have been successfully simulated. Also, it was found that there exists large sensible heat storage within the urban environment during the day, which is later released in the afternoon and at night in the city of São Paulo (not shown here). It was under clear sky conditions (Figure 4a) on 12 January 2015, so solar irradiance heated the Serra do Mar scarp (Figure 2c) developing the SBC and enhancing convergence at 1545 UTC, well simulated by both tTEB and control runs (Figure 15-first row). Cloudiness increased due to the intrusion of the SBC at 1530 UTC (not shown). Figure 15 (first row) shows a convergence front up to $1200 \mathrm{~m}$ height associated with the incoming SBC centered at $23.9^{\circ} \mathrm{S}$ for the tTEB run, and at $23.92^{\circ} \mathrm{S}$ for the control run with maximum of $16 \times 10^{-4} \mathrm{~g} \mathrm{~kg}^{-1} \mathrm{~s}^{-1}$ at 1545 UTC.

The more forward position of the convergence front in the tTEB run was caused by the UHI that accelerates the SBC towards the urban area of the MASP region. This faster propagation upwind of the MASP was caused by the horizontal pressure gradient pointing to the coast generated by coupling the UHIC and the SBC front. Once the SBC front reached the urban area of the MASP, stronger convergence zone generated above the city as well as the thermal circulations induced by the MASP acting halting the SBC for about two hours and advecting large amounts of moisture from the surface to the upper atmosphere [23,24].

The vertical cross sections of moisture divergence flux at 1830 UTC for tTEB and control runs and their difference field (Figure 15-second row) indicate higher divergence for tTEB than the control run associated to downdrafts and gust fronts over the urban area of the MASP (Figure 8c). The difference in moisture divergence flux between them reached $8 \times 10^{-4} \mathrm{~g} \mathrm{~kg}^{-1} \mathrm{~s}^{-1}$ up to $800 \mathrm{~m}$ height. At $23.25^{\circ} \mathrm{S}$ strong convergence was $-21 \times 10^{-4} \mathrm{~g} \mathrm{~kg}^{-1} \mathrm{~s}^{-1}$ for both runs as the SBC moves northward of the urban area of the MASP (Figure 12-second row). However, for the tTEB run, the convergence front lagged behind the control run due to urban canopy roughness.

Figure 16 (first row) shows that the horizontal wind speed above the urban area of the MASP is reduced down to $10 \mathrm{~m} \mathrm{~s}^{-1}$ at the surface for the tTEB experiment in comparison with the control experiment at 1830 UTC due to the urban canopy roughness effects. Higher wind speed differences between tTEB and control runs was caused by storm gusts along the east coast of the of the MASP. Figure 16 (second row) shows the vertical cross- section of the wind speed for the tTEB and control runs at 1830 UTC. The sea-breeze front in the tTEB run was at $23.25^{\circ} \mathrm{S}$ with wind speeds between $11 \mathrm{~m} \mathrm{~s}^{-1}$ to $6 \mathrm{~m} \mathrm{~s}^{-1}$ below $1500 \mathrm{~m}$, while in the control run they were between $13 \mathrm{~m} \mathrm{~s}^{-1}$ to $8 \mathrm{~m} \mathrm{~s}^{-1}$ below $3000 \mathrm{~m}$ at $23.23^{\circ} \mathrm{S}$. So, the sea-breeze front was delayed in the tTEB run by $0.03^{\circ}$ in comparison with the sea-breeze front in the control run with maximum wind speed difference of $5 \mathrm{~m} \mathrm{~s}^{-1}$. Noteworthy, the sea breeze front and divergence-convergence patterns were affected by downdrafts and gust fronts over the urban area of the MASP, described in Section 5.3.3. 

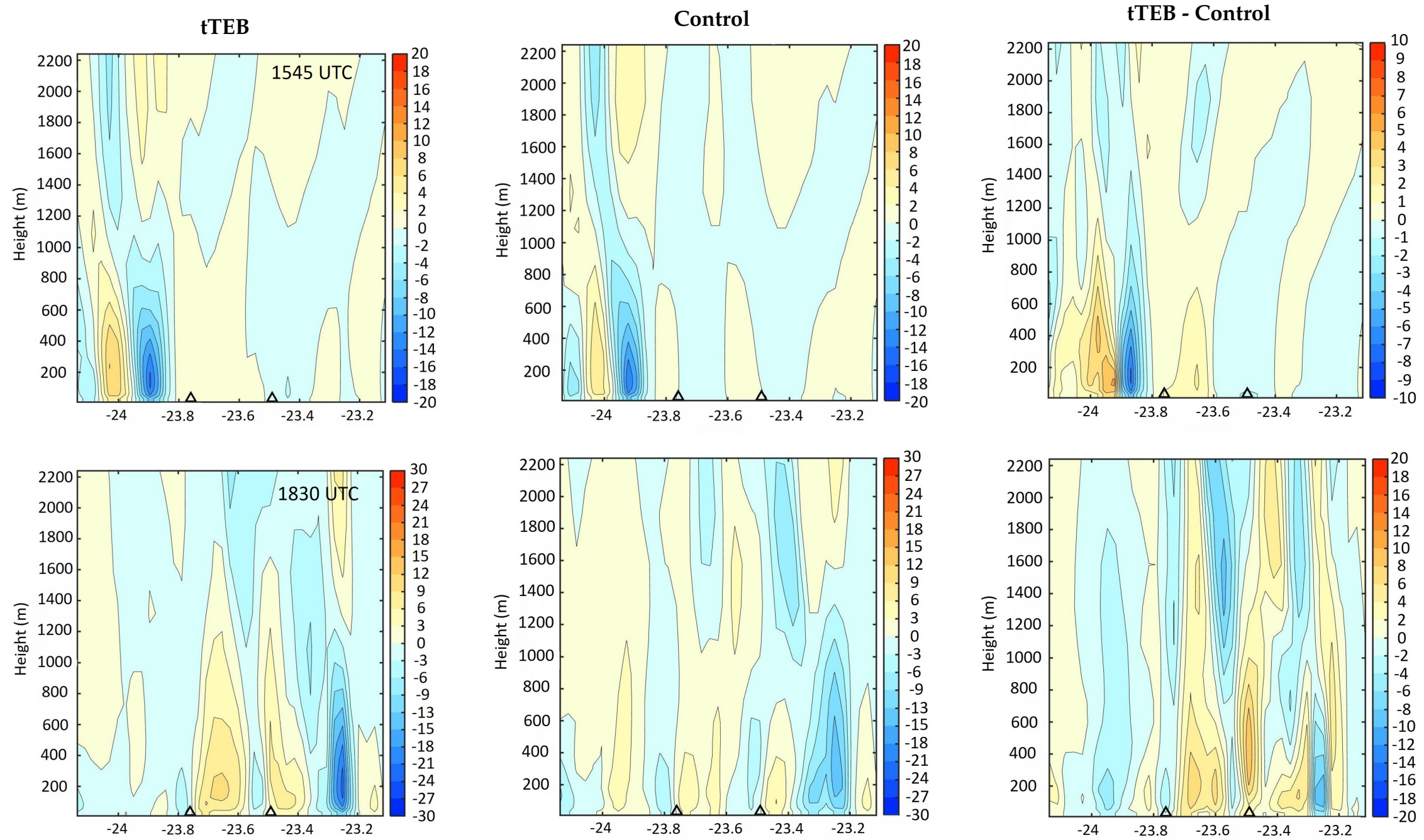

Figure 15. Vertical cross section of the mean moisture divergence flux $\left(\times 10^{-4} \mathrm{~g} \mathrm{~kg}^{-1} \mathrm{~s}^{-1}\right)$ between $46.90^{\circ} \mathrm{W}$ and $46.42^{\circ} \mathrm{W}$ at $1545 \mathrm{UTC}(1245 \mathrm{LT})$ (first row) and 1830 UTC (1530 LT) (second row) along the latitude. The figure shows the results of the tTEB experiment (first column), control experiment (second column) and the differences between both experiments (third column). Triangles indicate the extension of the urban area of the MASP. 

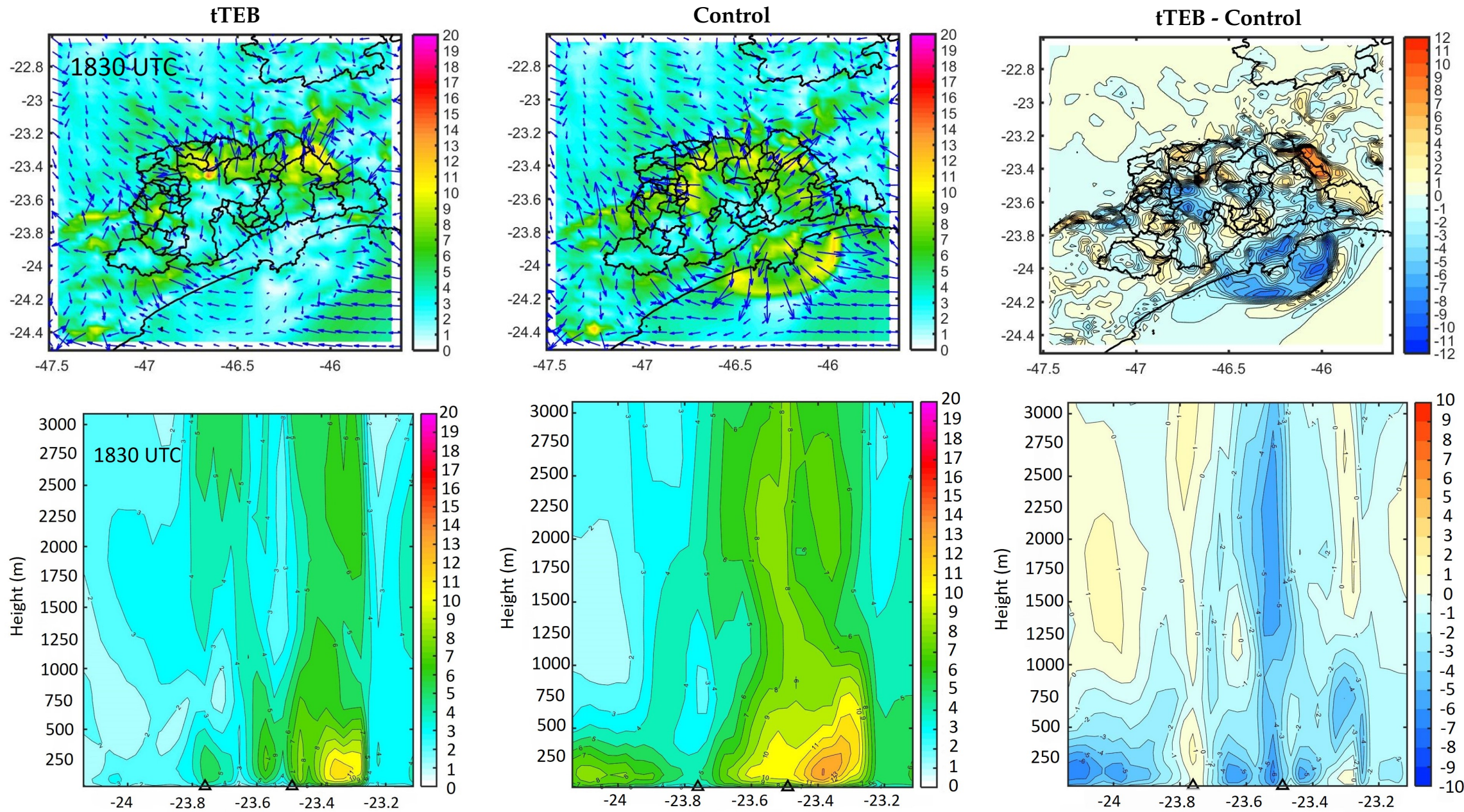

Figure 16. First row: Wind velocity vectors and wind magnitude $\left(\mathrm{m} \mathrm{s}^{-1}\right)$ at the first level of the model at 1830 UTC (1530 LT). Second row: Vertical cross section of mean horizontal wind magnitude $\left(\mathrm{m} \mathrm{s}^{-1}\right.$ ) between $46.9^{\circ} \mathrm{W}-46.42^{\circ} \mathrm{W}$ at $1830 \mathrm{UTC}$ (1530 LT) along the latitude. The figure shows the results of tTEB experiment (first column), control experiment (second column) and the differences between both experiments (third column). Triangles indicate the extension of urban canopy of the MASP. 


\subsubsection{Rain Water and Hail Mixing Ratios}

The rain water mixing ratio increased both above and downwind of the MASP in the tTEB run, consistent with the analyzed divergence-convergence patterns in presented in Section 5.3.2. Figure 17 shows the vertical cross section of mean rain water mixing ratio between $46.9^{\circ} \mathrm{W}$ and $46.42^{\circ} \mathrm{W}$ at 1800 UTC and 1830 UTC on 12 January, 2015. The rain water mixing ratio increased to $1.6 \mathrm{~g} \mathrm{~kg}^{-1}$ up to $9 \mathrm{~km}$ height. Similarly, Figure 18 shows vertical cross sections of the hail mixing ratio with $0{ }^{\circ} \mathrm{C}$ and $-40{ }^{\circ} \mathrm{C}$ isotherms. Between these isotherms the Bergeron microphysics process was very efficient in producing ice and releasing latent heat energy. Similar to the rain mixing ratio, the hail mixing ratio increased up to $1.2 \mathrm{~g} \mathrm{~kg}^{-1}$ between $6 \mathrm{~km}$ and $10 \mathrm{~km}$ height above and downwind of MASP for the tTEB run.

Thermodynamic instability is key to hail formation under vigorous updrafts. In general, buoyancy across an updraft determines its magnitude. It is caused by instability and updrafts turbulent mixing with dry environments [59]. Turbulence is produced by the inflow of dry environmental air and wind shear in the vicinity of the updraft [60]. Figure 19 illustrates these processes by showing vertical cross section of mean TKE between $46.9^{\circ} \mathrm{W}$ and $46.42^{\circ} \mathrm{W}$ at 1800 UTC and 1830 UTC for the tTEB and control runs and their difference.

TKE contains terms for buoyant and mechanical production and redistribution by transport and pressure forces. Positive buoyant production occurs when there is heating at the surface so that an unstable temperature lapse rate develops near the ground and spontaneous convective overturning can occur [61]. TKE was higher above and downwind of the urban area of the MASP for the tTEB run with differences with the control run between $1 \mathrm{~m}^{2} \mathrm{~s}^{-2}$ and $6 \mathrm{~m}^{2} \mathrm{~s}^{-2}$ at altitudes between $6 \mathrm{~km}$ and $16 \mathrm{~km}$. This higher TKE generated an intensification of vertical motion and so, a greater production of hail (Figure 18).

The UHI dynamic and thermal effects and the increase of hail production above and downwind of cities are associated to enhanced lightning activity [62-64]. Particularly, by studying the urban effect on the cloud-to-ground lightning activity on the MASP, it was observed that the region of large activity was coincident with the location of the main urban areas with larger surface temperatures which was obtained from the thermal band of the LandSat-7 satellite [65]. 
tTEB
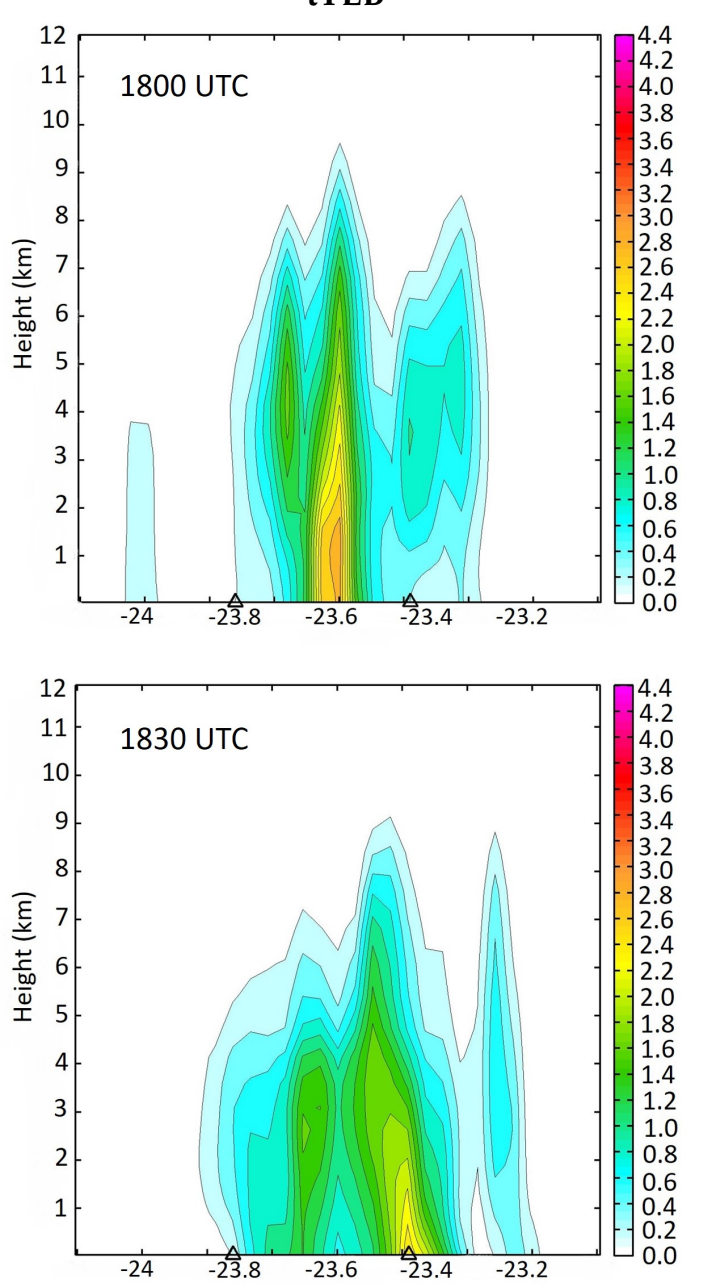

Control
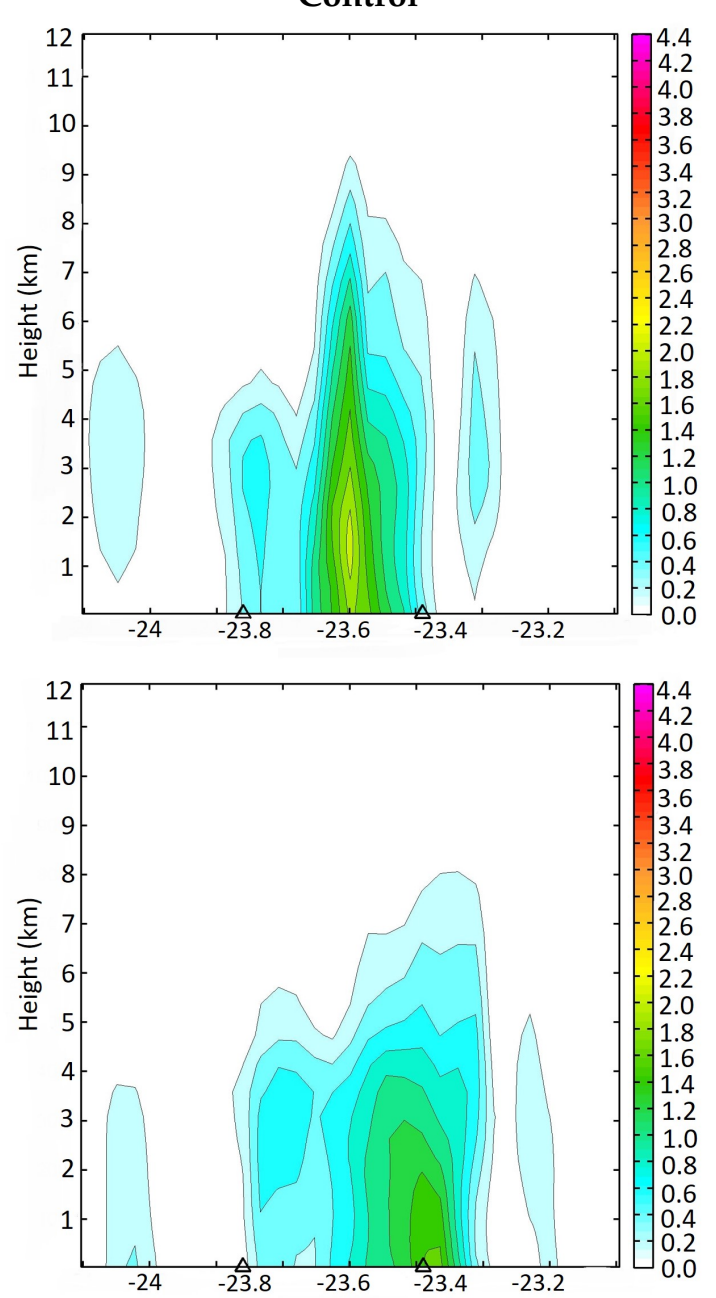

tTEB - Control
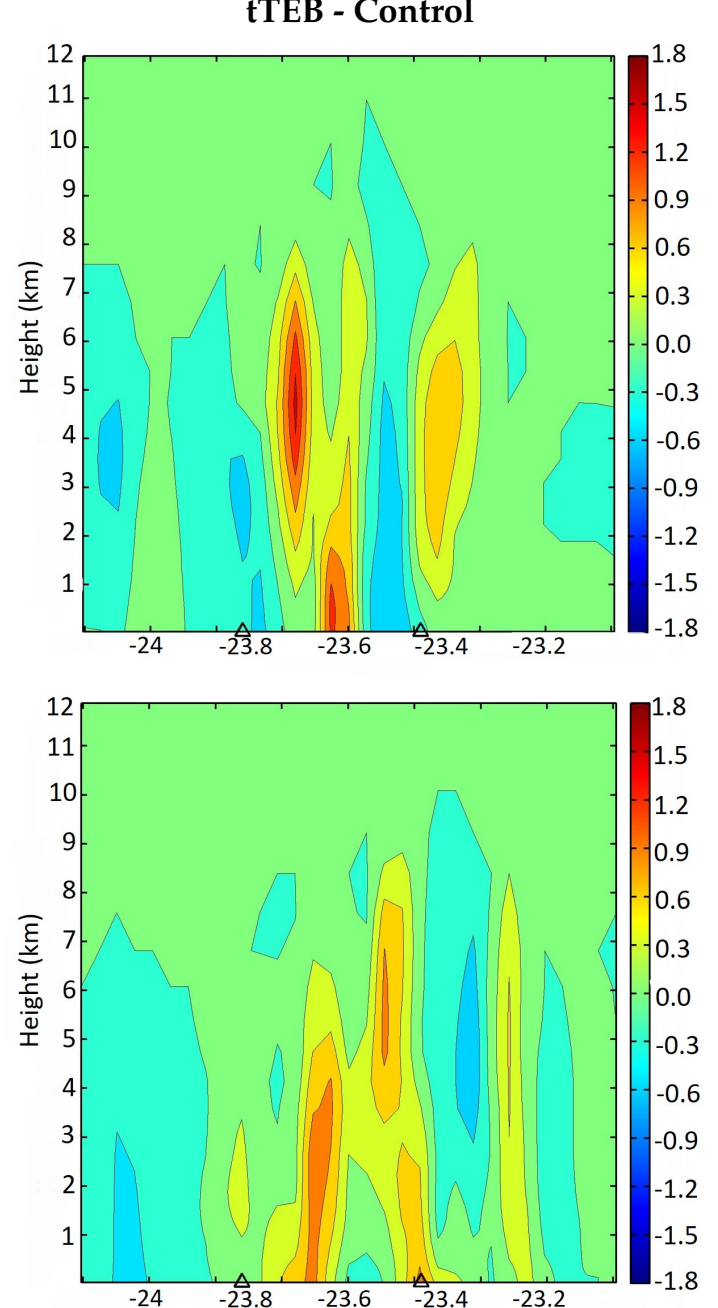

Figure 17. Vertical cross section of mean rain water mixing ratio $\left(\mathrm{g} \mathrm{kg}^{-1}\right)$ between $46.9^{\circ} \mathrm{W}$ and $46.42^{\circ} \mathrm{W}$ at $18 \mathrm{UTC}$ (15 LT) (first row) and $1830 \mathrm{UTC}$ ( $1530 \mathrm{LT}$ ) (second row) along the latitude. The first column shows the results of the tTEB experiment, the second column shows results of the control experiment and the third column show the differences between both experiments. Triangles indicate the extension of urban canopy of the MASP. 

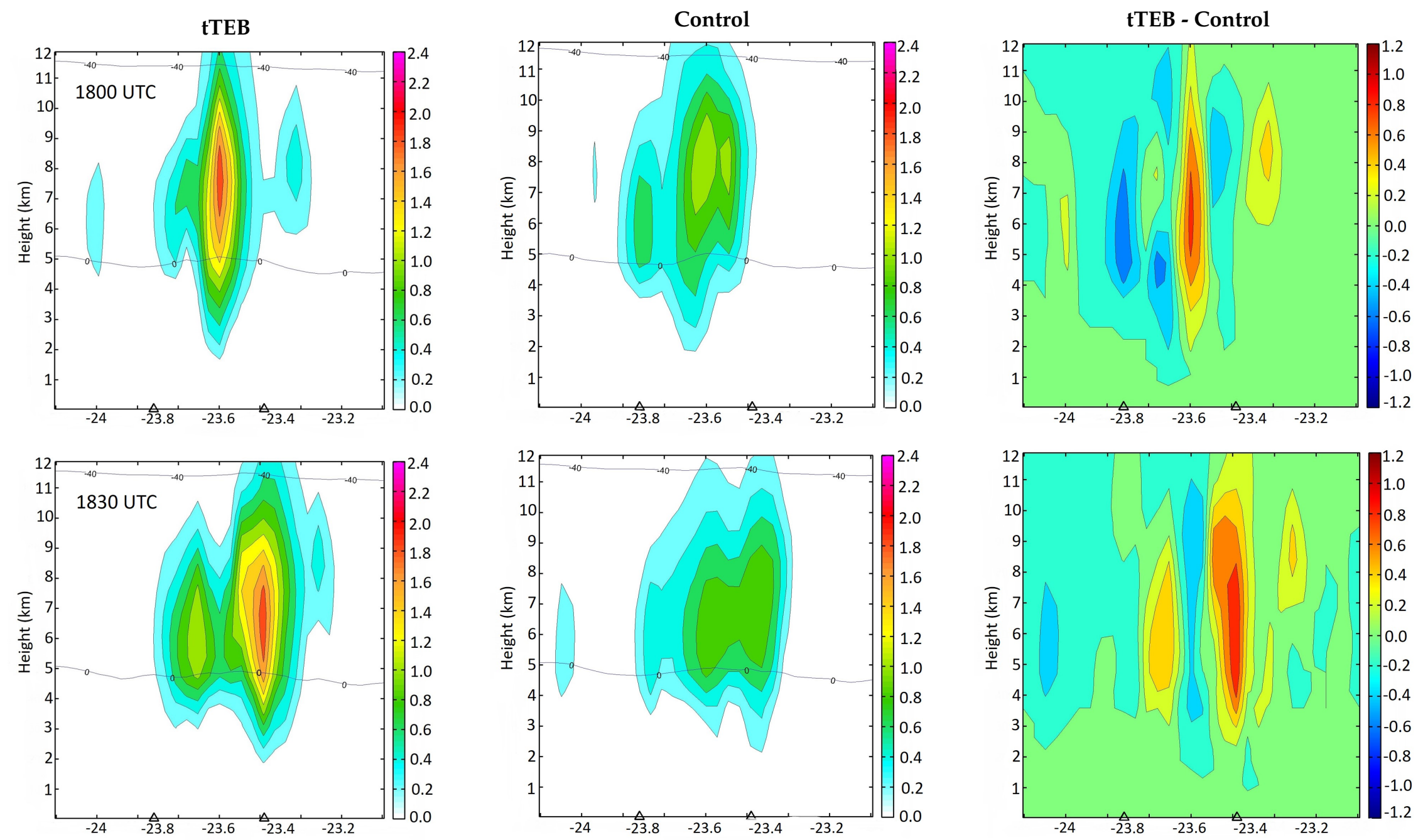

Figure 18. Vertical cross section of mean hail mixing ratio $\left(\mathrm{g} \mathrm{kg}^{-1}\right)$ between $46.9^{\circ} \mathrm{W}$ and $46.42^{\circ} \mathrm{W}$ at $18 \mathrm{UTC}$ (15 LT) (first row) and $1830 \mathrm{UTC}$ (1530 LT) (second row) along the latitude. The first column shows results of the tTEB experiment, the second column shows results of the control experiment and the third column shows the difference between both experiments. Contours of $0^{\circ} \mathrm{C}$ and $-40^{\circ} \mathrm{C}$ of air temperature are indicated. Triangles indicate the extension of the urban canopy of the MASP. 

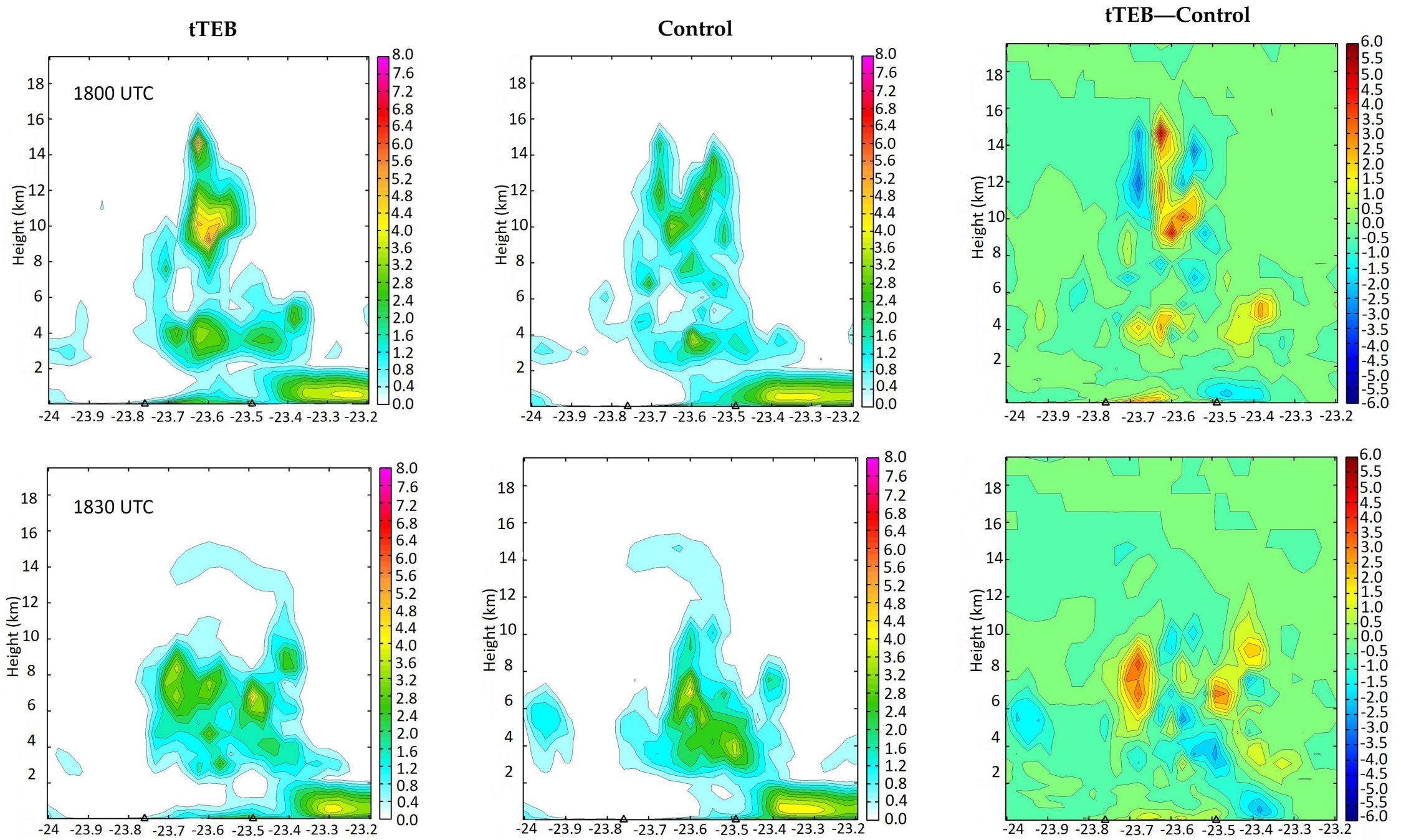

Figure 19. Vertical cross section of mean TKE $\left(\mathrm{m}^{2} \mathrm{~s}^{-2}\right.$ ) between $46.9^{\circ} \mathrm{W}$ and $46.42^{\circ} \mathrm{W}$ at (first row) $18 \mathrm{UTC}$ (15 LT) and (second row) $1830 \mathrm{UTC}$ (1530 LT). The first column shows the results of the tTEB experiment, the second column shows results of the control experiment, and the third column show the difference between both experiments. Triangles indicate the extension of urban canopy of the MASP. 


\section{Conclusions}

We performed a detailed analysis of the effects of an explicit three dimensional (3D) urban canopy representation on the generation of the UHI phenomenon and on the development of the heavy rainfall event occurring on 12 January 2015 above the MASP. Two experiments were performed, the first with the urban canopy (ARPS-tTEB run) and the second one with the default semi-desert canopy (control run).

As in other methods, the ARPS-tTEB system allows computing surface energy fluxes of sensible, latent and momentum generated by the urban landscape that modifies energy and water budgets and, consequently, the boundary layer of urban environment. The results indicate that the urban environment enhances the vertical extension, horizontal area and intensity of the UHI during day and night periods. The ARPS-tTEB run modified SEB terms in urban areas with lower in latent heat flux and significantly higher sensible and heat storage over urban surfaces. It is subsequently released to the lower atmosphere during night time, contributing to the strengthening of the UHI.

Higher roughness over urban canopies and the UHI phenomenon induce local circulation that in turn accelerates the SBC toward the MASP and increasing boundary layer convergence downwind it. Higher convergence above and downwind of MASP halts the SBC and injects high moisture content to vigorous updrafts and yielding higher precipitation above and downwind of MASP and also produce higher hail and rainfall downwind of the MASP result greater lightning activity. The ARPS-tTEB run produced more intense boundary layer circulation from the UHIC and the SBC. Spatial pattern of precipitation simulated by the ARPS-tTEB run was $8 \%$ more a more accurate than the control run compared against CMORPH, GPM and SPWR precipitation estimates. Comparison of ARPS-tTEB precipitation time series with SPWR precipitation estimates using a Bayesian analysis has up to three times more similarity on the average effect size parameter than one for the control run.

One of the limitations of the present work is the aerosol effect which has been shown as an important factor that affect precipitation processes above the MASP [66]. The drop concentration generated by urban rich cloud condensation nuclei(CCN) augmentation by air pollution is in general greater then the ones observed in the Amazon Forest during the Large Scale Biosphere-Atmosphere Experiment in the Amazon (LBA) [67]. Moreover, measurements of CCN performed from 16 to 31 October 2012 in the MASP show an increase in aerosol hygroscopicity in the afternoon as a result of aerosol photochemical processing, leading an increase in aerosol average diameter and an enhancement of both organic and inorganic secondary aerosols in the atmosphere [68]. However, for the city of St. Louis, Missouri, has been shown that urban-forced convergence downwind of the city, rather than the presence of greater aerosol concentrations, determines whether storms actually develop in the downwind region. The results show that the effects of aerosols influence the rate and amount of liquid water and ice produced within these storms and the accumulated surface precipitation among other storm features [69]. Another limiting factor is the use of constant parameters such as albedo, emissivity, geometric features of the urban environment and anthropogenic fluxes. Further work is under way to include more detailed urban features.

Author Contributions: For the present work, the contributions were distributed as follows: "conceptualization, J.L.F.-R. and A.J.P.-F.; methodology, J.L.F.-R., H.A.K. and V.M.; software, A.J.P.-F. and J.L.F.-R.; validation, J.L.F.-R., A.J.P.-F. and F.V.; formal analysis, J.L.F.-R. and F.V.; investigation, J.L.F.-R., H.A.K. and V.M.; resources, A.J.P.-F., H.A.K. and F.V.; data curation, J.L.F.-R. and F.V.; writing—original draft preparation, J.L.F.-R.; writing-review and editing, J.L.F.-R.; visualization, J.L.F.-R. and F.V.; supervision, A.J.P.-F., H.A.K. and V.M.; project administration, A.J.P.-F. and F.Y.S.-V.; funding acquisition, A.J.P.-F. and F.Y.S.-V."

Funding: The authors wish to thank to CNPQ agency (Grant 302349/20146) for providing financial support during the period of research. The second author is sponsored by Conselho Nacional de Desenvolvimento Científico e Tecnológico (CNPq) (Grant 302349/2017-6).

Acknowledgments: We thank to Ming Xue for very important suggestions to improve the present work. Part of the present work was done using computational resources, HPC-Linux-Cluster, from Laboratorio de Dinámica de Fluidos Geofísicos Computacionales at Instituto Geofísico del Perú (grants 101-2014-FONDECYT, SPIRALES2012 IRD-IGP, Manglares IGP-IDRC, PP068 program). 
Conflicts of Interest: The authors declare no conflict of interest.

\section{Abbreviations}

The following abbreviations are used in this manuscript:

$\begin{array}{ll}\text { ARPS } & \text { Advance regional prediction system } \\ \text { CMORPH } & \text { Climate Prediction Center Morphing Technique } \\ \text { CEMADEN } & \text { Centro Nacional de Monitoramento e Alertas de Desastres Naturais } \\ \text { GFS } & \text { Global Forecast System } \\ \text { GPM } & \text { Global Precipitation Measurement } \\ \text { NWP } & \text { Numerical Weather Prediction } \\ \text { tTEB } & \text { tropical Town Energy Budget scheme } \\ \text { SBC } & \text { sea-breeze circulation } \\ \text { MASP } & \text { Metropolitan area of São Paulo } \\ \text { SEB } & \text { Surface Energy Balance } \\ \text { SPWR } & \text { São Paulo weather radar } \\ \text { SST } & \text { Sea Surface Temperature } \\ \text { TRMM } & \text { Tropical Rainfall Measurement Mission }\end{array}$

\section{References}

1. Markowsky, P.; Richardson, Y. Mesoscale Meteorology in Midlatitudes, 1st ed.; Wiley-Blackwell: Hoboken, NJ, USA, 2010.

2. Browning, K. Airflow and precipitation trajectories within severe storms that move to the right of the winds. J. Atmos. Sci. 1964, 21, 634-639. [CrossRef]

3. Klemp, J. Dynamics of tornadic thunderstorms. Annu. Rev. Fluid Mech. 1987, 59, 369-402. [CrossRef]

4. Weisman, M.; Klemp, J. The structure and clasification of numerically simulated convective storms in directionally varying wind shears. Mon. Weather Rev. 1984, 112, 167-170. [CrossRef]

5. Xue, M.; Droegmeier, K.; Wong, V. The Advanced Regional Prediction System (ARPS)—A multi-scale nonhydrostatic atmospheric simulation and prediction model. Part I: Model Dynamics and Verification. Meteorol. Atmos. Phys. 2000, 1, 1-45. [CrossRef]

6. Shepherd, J.M. A Review of Current Invetigations or Urban-Induced Rainfall and Recommendations for the future. Earth Interact. 2005, 9, 1-12. [CrossRef]

7. Buhaug, H.; Urdal, H. An urbanization bomb? Population growth and social disorder in cities. Glob. Environ. Chang. 2013, 23, 1-10. [CrossRef]

8. Erell, E.; Pearlmutter, D.; Williamson, T. Urban Microclimate. Design the Spaces between Buildings, 1st ed.; Earthscan: Washington, DC, USA, 2011.

9. Oke, T. Boundary Layer Climates, 1st ed.; Taylor and Francis Group: New York, NY, USA, 1987; p. 435.

10. Bornstein, R.; Lin, Q. Urban heat islands and summertime convective thunderstorms in Atlanta: Three cases studies. Atmos. Environ. 2000, 34, 507-516. [CrossRef]

11. Huff, H. Urban hydrological review. Bull. Am. Meteorol. 1986, 67, 703-712. [CrossRef]

12. Changnon, S., Jr.; Huff, F.; Schickendanz, P.; Vogel, J. Summary of METROMEX, Vol. 1: Weather anomalies and impacts. Bull. Am. Meteorol. Soc. 1977, 62, 260.

13. Huff, F.; Vogel, J. Urban, topographic and diurnal effects on rainfall in the St. Louis region. J. Appl. Meteorol. 1978, 17, 565-577. [CrossRef]

14. Sanderson, M.; Gorski, R. The effect of metropolitan Detroit-Windsor on precipitation. J. Appl. Meteorol. 1977, 17, 423-427. [CrossRef]

15. Pereira Filho, A.; Barros, M.; Hallak, R.; Gandu, A. Enchentes na região metropilitana de São Paulo: Aspectos de mesoescala e avaliação de impactos. In Proceedings of the XIII Congresso Brasileiro de Meterologia, Fortaleza, Brazil, 28 August-9 Setember 2004.

16. Vemado, F.; Pereira Filho, A. Severe weather caused by Heat Island and Sea breeze effects in the Metropolitan Area of São Paulo, Brazil. Adv. Meteorol. 2016, 2016, 8364134. [CrossRef]

17. Karam, H.; Oliveira, A.; Soares, J. Application of mass conservation method to investigate the wind patterns over an area of complex topography. J. Braz. Soc. Mech. Sci. Eng. 2003, 25, 115-121. [CrossRef] 
18. Masson, V. A physically-based scheme for the urban energy budget in atmospheric models. Bound.-Layer Meteorol. 2000, 94, 357-397. [CrossRef]

19. Cotton, W.; Pielke, R., Sr.; Walko, R.; Liston, G.; Tremback, C.; Jiang, H.; Mcanelly, R.; Harrington, J.; Nicholls, M.; Carrio, G.; et al. RAMS 2001: Current status and future directions. Meteorol. Atmos. Phys. 2003, 82, 5-39. [CrossRef]

20. Rozoff, C.; Cotton, W.; Adegoke, J. Simulation of St. Louis, Missouri, land use impacts on thunderstorms. J. Appl. Meteorol. 2003, 42, 716-738. [CrossRef]

21. Lei, M.; Niyogi, D.; Kishtawal, C.; Pielke, R.A., Sr.; Beltrán-Przekurat, A.; Nobis, T.E.; Vaidya, S.S. Effect of explicit urban land surface representation on the simulation of the 26 July 2005 heavy rain event over Mumbai, India. Atmos. Chem. Phys. 2008, 8, 5975-5995. [CrossRef]

22. Karam, H.; Pereira Filho, A.; Masson, V.; Noilhan, J.; Marques Filho, E. Formulation of a tropical town energy budget (t-TEB) scheme. Theor. Appl. Climatol. 2010, 101, 109-120. [CrossRef]

23. Rojas, J.F.; Pereira Filho, A.; Karam, H.; Vemando, F.; Masson, V. Effects of Explicit Urban-Canopy Representation on Local Circulations Above a Tropical Mega-City. Bound.-Layer Meteorol. 2018, 166, 83-111. [CrossRef]

24. Freitas, E.; Rozoff, C.; Cotton, W.; Silva Dias, P. Interacions of an urban heat island and sea-breeze circulations during winter over the metropolitan area of São Paulo, Brazil. Bound.-Layer Meteorol. 2007, 122, 43-65. [CrossRef]

25. Oliveira de Souza, D.; dos Santos Alvalá, R.; Guedes do Nascimento, M. Urbanization effects on the microclimate of Manaus: A modeling study. Atmos. Res. 2016, 167, 237-248. [CrossRef]

26. Pereira Filho, A.; Vemado, F.; Saito, K.; Seko, H.; Karam, H. ARPS Simulations of Convection during TOMACS. J. Meteorol. Soc. Jpn. 2018, 96A, 247-263. [CrossRef]

27. Ikeda, R.; Kusaka, H. Proposing the Simplification of the Multilayer Urban Canopy Model:Intercomparison Study of Four Models. J. Appl. Meteorol. Climatol. 2009, 49, 902-919. [CrossRef]

28. Porson, A.; Clark, P.; Harman, I.; Best, M.; Belchera, S. Implementation of a new urban energy budget schemeinto MetUM. Part II: Validation against observations and model intercomparison. Q. J. R. Meteorol. Soc. 2010, 136, 1530-1542. [CrossRef]

29. Grimmond, C.S.B.; Blackett, M.; Best, M.; Baik, J.J.; Belcher, S.; Beringer, J.; Bohnenstengel, S.; Calmet, I.; Chen, F.; Coutts, A.; et al. Initial results from Phase 2 of the international urban energy balance model comparison. Int. J. Climatol. 2011, 31, 244-272. [CrossRef]

30. IBGE. Demographics Censuses; IBGE: Rio de Janeiro, Brazil, 2011.

31. United Nations. Population Facts-Our urbanizing world. Dep. Econ. Soc. Aff. Popul. Div. 2014, 1, 1-4.

32. Narcizo de Lima, G.; Mañaga Rueda, V. The urban growth of the metropolitan area of Sao Paulo and its impact on the climate. Weather Clim. Extrem. 2018, 21, 17-26. [CrossRef]

33. Muller, G.; Ambrizzi, T.; Nuñez, M. Mean atmospheric circulation leading to generalized frosts in Central Southern South America. Theor. Appl. Climatol. 2005, 82, 95-112. [CrossRef]

34. Hidalgo Nunes, L.; Koga Vicente, A.; Henrique Candido, D. Tempo e Clima no Brasil—Clima da Região Sudeste do Brasil, 2nd ed.; Climatologia Regional: São Paulo, Brazil, 2015; pp. 243-256.

35. Businger, J.; Wyngaard, J.; Izumi, Y.; Bradley, E. Flux-profile relationships in the atmospheric surface layer. J. Atmos. Sci. 1971, 28, 181-189. [CrossRef]

36. Byun, D. On the analytical solutions of flux-profile relationships for the atmospheric surface layer. J. Appl. Meteorol. 1990, 29, 652-657. [CrossRef]

37. Deardorff, J. Parameterization of the planetary boundary layer for use in general circulation models. Mon. Weather Rev. 1972, 100, 93-106. [CrossRef]

38. Martilli, A.; Clappier, A.; Rotach, M. An urban surface exchange parameterization for mesoscale models. Bound.-Layer Meteorol. 2002, 104, 261-304. [CrossRef]

39. Arnfield, A.; Mills, G. An analysis of the circulation characteristics and energy budget of a dry, asymmetric, eastwest urban canyon II. Energy budget. Int. J. Climatol. 1994, 14, 239-261. [CrossRef]

40. Grimmond, C.; Oke, T. An evapotranspiration interception model for urban areas. Water Resour. Res. 1991, 27, 1739-1755. [CrossRef]

41. Schultz, P. An explicit cloud physics paramterization for operational numerical weather prediction. Mon. Weather Rev. 1995, 123, 3331-3343. [CrossRef] 
42. Kain, J.; Fritsch, J. Convective parameterization for mesoscale models: The Kain Fritsch scheme. The Representation of Cumulus Convection in Numerical Mode. Meteorol. Monogr. 1993, 24, 165-170.

43. Grimmond, C.; Oke, T. Aerodynamic properties of urban areas derived from analysis of surface form. J. Appl. Meteorol. 1999, 38, 1262-1292. [CrossRef]

44. Kastner-Klein, P.; Rotach, M. Mean flow and turbulence characteristics in an urban roughness sublayer. Bound.-Layer Meteorol. 2003, 111, 55-84. [CrossRef]

45. Flores Rojas, J.; Pereira Filho, A.; Karam, H. Estimation of long term low resolution surface urban heat island intensities for tropical cities using MODIS remote sensing data. Urban Clim. 2016, 17, 32-66. [CrossRef]

46. Tarifa, J.; Azevedo, T. Os Climas na Cidade de São Paulo: Teoria e Prática, 1st ed.; FFLCH/USP: São Paulo, Brazil, 2001.

47. Noilhan, J.; Planton, S. A simple parameterization of land surface processes for meteorological models. Mon. Weather Rev. 1989, 117, 536-549. [CrossRef]

48. Baldwin, M.; Kain, J. Sensitivity of several performance measures to displacement error, bias and event frequency. Weather Forecast. 2005, 21, 636-648. [CrossRef]

49. Mesinger, F.; Brill, K. Bias normalized precipitation score. In Proceedings of the 17th Conferences on Probability and Statistics, Seattle, WA, USA, 11-15 January 2004; Volume 77.

50. Murphy, A. What is a good forecast? An essay on the nature of goodness in weather forecasting. Weather Forecast. 1993, 8, 281-293. [CrossRef]

51. Tartaglione, N. Relationship between precipitation forecast errors and skill scores of dichotomous forecasts. Am. Meteorol. Soc. 2009, 25, 355-365. [CrossRef]

52. Kruschke, J. Bayesian Estimation Supersedes the t Test. J. Exp. Psychol. 2013, 142, 573-603. [CrossRef] [PubMed]

53. Centro de Gerenciamento de Emergencias. Alagamentos; Centro de Gerenciamento de Emergencias: São Paulo, Brazil, 2015.

54. CEMADEN. Centro Nacional de Monitoramento e Alertas de Desastres Naturais; CEMADEN: São Paulo, Brazil, 2015.

55. Ferreira, M.; Oliveira, A.; Soares, J.; Codato, G.; Bárbaro, E.; Escobedo, J. Radiation balance at the surface in the city of São Paulo, Brazil: Diurnal and seasonal variations. Theor. Appl. Climatol. 2011, 107, 229-246. [CrossRef]

56. de Morais, M.; de Freitas, E.; Marciotto, E.; Guerrero, V.; Martins, L.; Martins, J. Implementation of Observed Sky-View Factor in a Mesoscale Model for Sensitivity Studies of the Urban Meteorology. Sustainability 2018, 10, 2183. [CrossRef]

57. Shem, W.; Shepherd, M. On the impact of urbanization on summertime thunderstorms in Atlanta: Two numerical model case studies. Atmos. Res. 2009, 92, 179-189. [CrossRef]

58. Holt, T.; Niyogi, D.; Chen, F.; LeMone, M.A.; Manning, K.; Qureshi, A.L. Effect of Land- Atmosphere Interactions on the IHOP 24-25 May 2002 Convection Case. Mon. Weather Rev. 2006, 134, 113-133. [CrossRef]

59. Cotton, W. Storm and Cloud Dynamics, 1st ed.; International Geophysical Series; Academic Press: Cambridge, MA, USA, 2011.

60. Knupp, K.R.; Cotton, W.R. An intense, quasi-steady thunderstorm over mountainous terrain-Part III: Doppler radar observations of the turbulence structure. J. Atmos. Sci. 1982, 39, 359-368. [CrossRef]

61. Holton, J. An Introduction to Dynamic Meteorology, 4th ed.; Elsevier Academic Press: Cambridge, MA, USA, 2004.

62. Changnon, S. Temporal and spatial relations between hail and lightning. Am. Meteorol. Soc. 1992, 31, 587-604. [CrossRef]

63. Pinto, I.R.; Pinto, O., Jr.; Gomes, M.A.; Ferreira, N.J. Urban effect on the characteristics of cloud-to-ground lightning over Belo Horizonte. Ann. Geophys. 2004, 22, 697-700. [CrossRef]

64. Pereira Filho, A. A mobile X-POL weather radar for hydrometeorological applications in the metropolitan area of São Paulo, Brazil. Geosci. Instrum. Methods Data Syst. 2012, 1, 169-183. [CrossRef]

65. Naccarato, K.P.; Pinto, O., Jr.; Pinto, I.R. Evidence of thermal and aerosol effects on the cloud-to-ground lightning density and polarity over large urban areas of Southeastern Brazil. Geophys. Res. Lett. 2003, 30. [CrossRef] 
66. Pereira Filho, A.; Vemado, F.; Perez, J.; Da Silva, I., Jr.; Tanaka, J. Measurements of Drop Size Distribution in a Megacity. In Proceedings of the 36th Radar Conference, Breckenridge, CO, USA, 16-20 September 2013; Volume 2A3, pp. 1-5.

67. Pereira Filho, A.; Dias, M.; Albrecht, R.; Pereira, L.; Gandú, A.; Tokay, A. Multisensor analysis of a squall line in the Amazon Region. J. Geophys. Res. 2002, 107, 8084-8095. [CrossRef]

68. Almeida, G.; Brito, J.; Morales, C.; Andrade, M.; Artaxo, P. Measured and modelled cloud condensation nuclei $(\mathrm{CCN})$ concentration in São Paulo, Brazil: The importance of aerosol size-resolved chemical composition on CCN concentration prediction. Atmos. Chem. Phys. 2014, 14, 7559-7572. [CrossRef]

69. Van den Heever, S.; Cotton, W. Urban Aerosol Impacts on Downwind Convective Storms. J. Appl. Meteorol. Climatol. 2006, 46, 828-850. [CrossRef]

(C) 2019 by the authors. Licensee MDPI, Basel, Switzerland. This article is an open access article distributed under the terms and conditions of the Creative Commons Attribution (CC BY) license (http:/ / creativecommons.org/licenses/by/4.0/). 